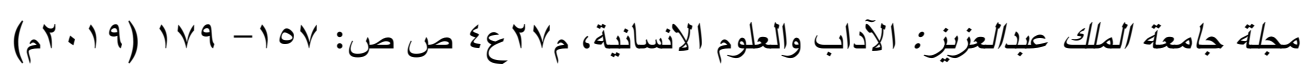

DOI:10.4197/Art.27-4.6

\title{
قصيدة المديح الإحيائية: البيعة والخلافة
}

\author{
عبد المعين حسن عبد الحميد بالفاس \\ كلية الآداب والعلوم الانسانية-جامعة الملك عبد العزيز \\ جلة - المدلكة العربية السعودية
}

مستخلص. يهدف هذا البحث إلى دراسة قصيدة مديح يحتفي من خلالها الشاعر حافظ إبراهيم بالمكانة الشعرية

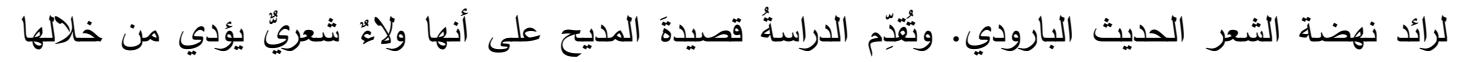
الثاعر حافظ إبراهيم البيعة لمدوحه بالخلافة الشعرية من جهة، ويطلب الخلافة الشعرية لنفسه من بعده من جهة أخرى. ولتأييد الطريقة الوصفية التي تستخدم التحليل النقدي للنصوص الشعرية تركز الدراسة على مفاهيم أساسية، أهمها: قصيدة مديح حافظ إبراهيم كمعارضة شعرية لداليّة المتنبي، وصوت حافظ الشعري، وإعادة تشكيل بنية القصيدة التقليدية بما فيها من أغراض وأقسام، وأهمية معيار الفضيلة الخلقية كعامل أساسي في

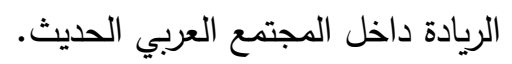

الكلمات المفتاحية: حافظ إبراهيم، البارودي، المتنبي، الخلافة الشعرية، البيعة الشعرية.

وطلب أحقية وراثتها/الاستخلاف لاستكمال المشروع

$$
\text { الإحيائي من جهة أخرى. }
$$

خلال هذه المقاربة النقدية يركز البحث على على لإنى عدد من المفاهيم المترابطة التي تثترك في دعم قضية البيعة والخلافة الشعريتين. من هذه المفاهيم

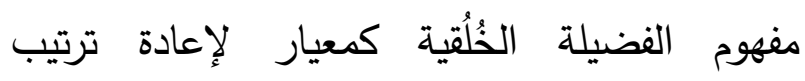

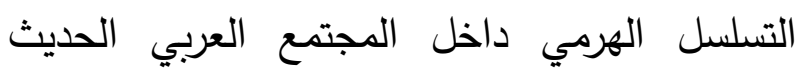
وكعامل أساسي لاستحقاق الخلافة الشعرية، ومفهوم

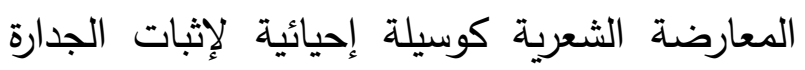

\section{المقدمة}

يناقش البحث قصيدة مديح دالية أنثدها

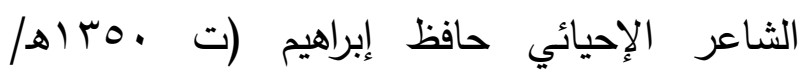

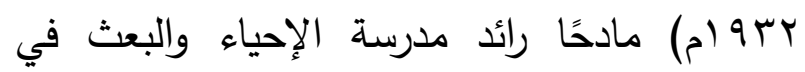

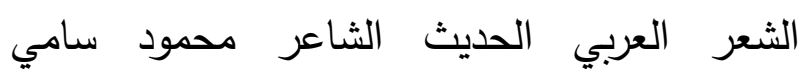

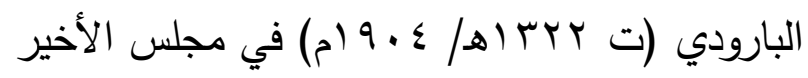
بعد عودته من المنفى؛ كوسيلة لإعلان البيعة

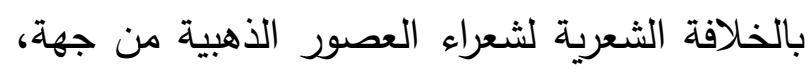


كُتبتُ بواسطة شاعر إحيائي شاب في بداية طريقه إلى شاعر إحيائي آخر كان في سنيّ عمره الأخيرة

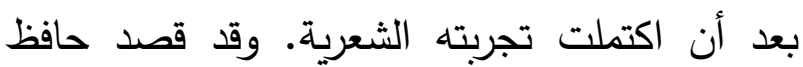
إبراهيم من قصيدته أمرين، هما: الاحتفاء بالمكانة

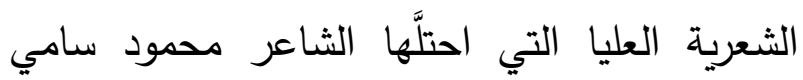
البارودي في عصره، ومبايعته بأمارة الشعر وطلب

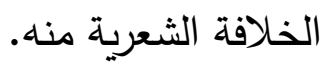
لقد كانت هناك علاقة ودٍّ وفكر تجمع الثاعرين الإحيائيين على المستويين الإنساني والأدبي تجعل الناظر في حاليهما يستشعر الترابط الذي يفضي إلى الإسي تقبل فكرة الامتداد التاريخي بينهما. أشار أحمد أمين في مقدمته لديوان حافظ إبراهيم إلى اتخاذ الأخير

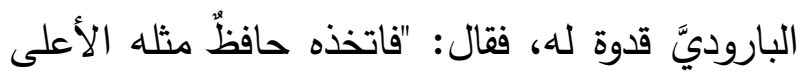
يحذو حذوه، ويختط منهجه، ويأمل أن يبلغ في

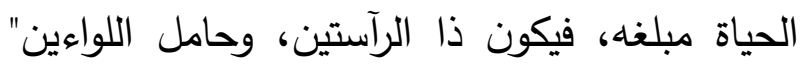
(إبراهيم، 9Av 19 ). ويقصد أحمد أمين بالرآستين

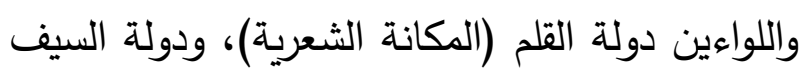
(المكانة السياسية). وقد استدل أحمد أمين بأبيات

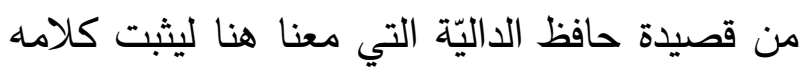

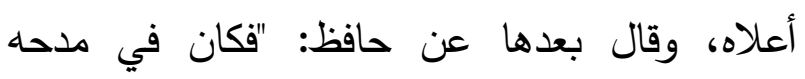
البارودي يرسم لنفسه مثله، ويحدد مستقبله" (إبراهيم، . (1919

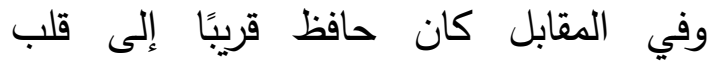
البارودي؛ فقد كان الأخير يكرم حافظًا ويقدّمه على ولى غيره من الشعراء. قال الحديدي في كتابه (محمود

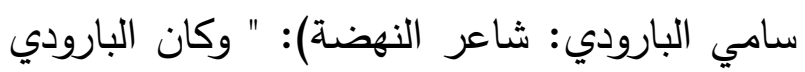

الشعرية؛ إذ قام حافظ إبراهيم بمعارضة داليّة أبي

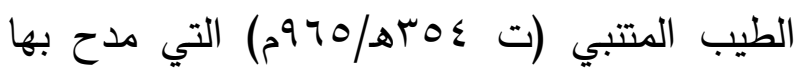

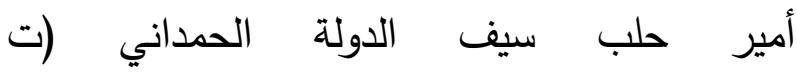

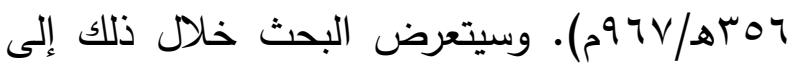

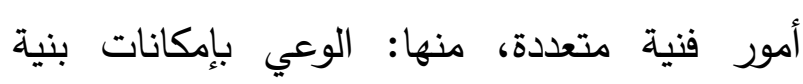

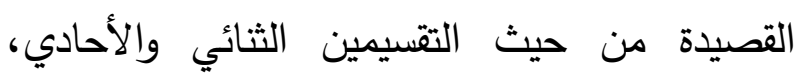
وبلاغة التلاعب بالتقليد الشعري القديم كالتلاعب بالأغراض الثعرية وما يتعلق به من حضور صوت بله الشاعر وغيابه.

ولدعم مقاربته النقدية يستحضر البحث آراءً في وعي بنية القصيدة التقليدية القديمة لبعض أئعة النقد العربي القديم كقدامة بن جعفر، وابن رشيق وابن لبن طباطبا والحاتمي والبغدادي والقرطاجني. بالإضافة إلى استحضاره لمفاهيم غربية معاصرة كمفهوم للفضيلة (virtue) Yaseen Noorani لاعتلاء الهرم الاجتماعي، وكيفية تحوّله من معيار

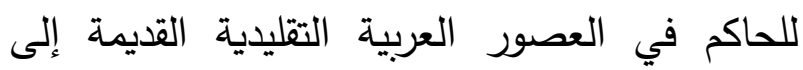
معيار للمحكوم في العصر الحديث، ومفاهيم Suzanne Stetkevych المديح، وللخبر المصاحب للقصيدة، ولعلاقة بنية القصيدة الكلاسيكية التقليدية بحالة الثاعر النفسية ووضعيْه الاجتماعي والسياسي من جهة، وعلاقتها بطبيعة علاقة الثاعر بمدوحه داخل الهرم الاجتماعي من جهة أخرى. مناسبة داليّة حافظ إبراهيم في مدح البارودي: من أسباب أهمية قصيدة حافظ إبراهيم الداليَّة أنها 
فما أثمت عيني ولا لحظــه اعتدى كلانا له عذر، فعذري شبيني وعذرك أني هِجـتُ سيفًا مجردًا ثم خاطب البارودي بعد أبيات فقال: أمير القوافي إن لي مستهامة

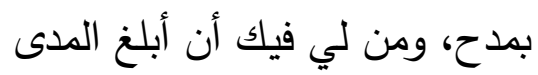
أعرني لمدحيك اليراع الذي به تخطّ، وأقرضني القريض المشددا(') واستطرد في مدح البارودي إلى أن قال: أتيتُ ولي نفس أطالت جدالها سيقضي عليها كرئها اليوم أو غدا فإن لم تداركها بفضـل فقد أتت تودعُ مـولاها وتستقبـل الردى لُع قال خليل مطران: فلما سمع الباروديٌٌ هذين البيتين بكى بكاء حارًّا، وناشد حافظا أن يحذفهما من القصيدة، ونهض من مكانه، ثم عاد وبيده ظرْف به أربعون جنيهًا ناوله حافظا، وهي قيمة ما كان مقررا للبارودي وقتئذ من معاش. ثم قال لحافظ: 'إني أبكي لأني عشتُ إلى زمن يقدم فيه مثلي إلى مثلك هذا المبلغ الضئيل'. وكأن البارودي بعد أن خرج حافظ قد استشعر اللوم من الصديق الثالث لأنه جاد بكل مرتبه دون أن يبقي لنفسه أو لأسرته شيئًا، ولم تكن أملاكه المصادرة قد رُدّتُ إليه، فيقول البارودي: لا تعذلني على وفر سمحتُ باه لمعتفين فإني

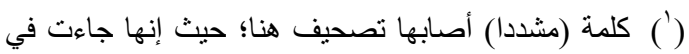

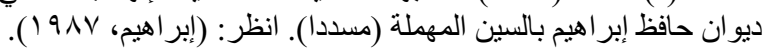

بينه وبين نفسه يؤثر بالوُدّ حافظًا على شوقي ولا يُظهر ذلك لأيّ منهما" (الحديدي، 979 (1)). وقد

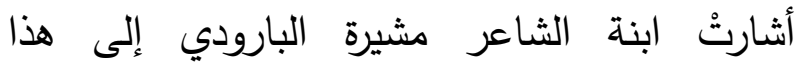
التفضيل بقولها: "فكان إذا أتى نبأ قدوم شوقي إليه تغضّن وجهه للحظات قصيرة فنعرف أنه لا يُسرّ للقائه، وخاصة في فترة تهجّمه في الصحف على عُرابي والثورة العُرابيّة إبان عودة عُرابي من منفاه

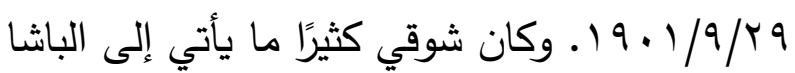
يطلب المطلْع لقصائده، وإذا ما جاء حافظ كانتُ تنفرجُ أساريره ويسرعُ للقائه" (الحديدي، 979 ( ). كما كان البارودي يهتم كثيرًا بما يكتبه حافظ من شعر، بل ويشجعه عليه في كل مناسبة، ومنها "حين أصدر حافظ الجز الأول من ديوانه عام 19.1 قرّظه البارودي بقصيدة أشاد فيها بفضله في دوحة القصيد، واستهلها بقوله:

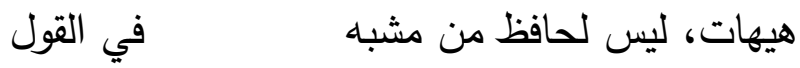
غير سميّه الثيرازي" (الحديدي، 9979 1). يجدر بالدراسة ابتداء الوقوف على مناسبة قصيدة حافظ إبراهيم في مدح البارودي؛ لاكتشاف دلالتها الرمزيـة لأهميتها في قراءة النص وتأويله. قال الحديدي: "وزاره [أيْ الباروديَّ] حافظٌ ذات يوم من أكتوبر عام . .9 1، وكان حافظ في ذلك الحين سيء الحال بعد عودته من السودان وإحالته إلى الاستيداع، فأنشد قصيدةً داليّة نظمها في البارودي وأشاد فيها بمناقبه، وبدأها بقوله:

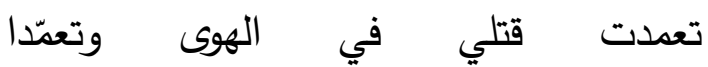


قضية (إحياء التقليد الشعري المصاحب لإلقاء مـاجد الثـيم

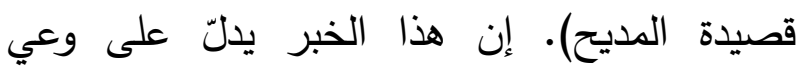
إن لم يكن للفتى جود يسدّ به مفاقر الصحب الثاعر البارودي بالتقاليد التراثية الثعرية العربية المصاحبة لإلقاء قصيدة المديح، ومنها التقليد الثعري العربي (الجائزة مقابل القصيدة). فالقصيدة

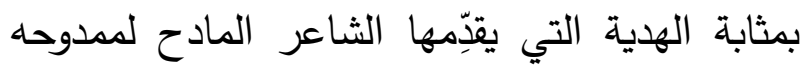

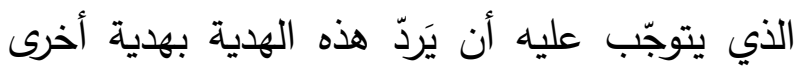

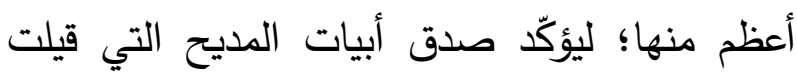

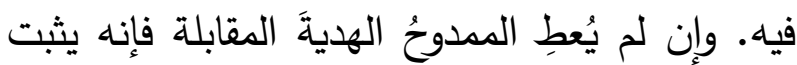
عدم أحقيتّه لما نُسب إليه من صفات في قصيدة

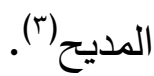
ومما يؤكد اتبّاع البارودي لهذا التقليد الشعري العربي ومحافظته عليه كوسيلة إحيائية للتراث العربي الأدبي ما قام به من إعطاء حافظ مالاً (جائزة) من دون أن يمدحه بصفة الكرم في قصيدته، حيث دلَّ ذلك دلالة واضحة على أن اتّاع البارودي للتراث الثقافي الشعري -بما فيه من علاقة خاصة بين الثاعر والممدوح- يقضي بضرورة مكافأة الثاعر المادح

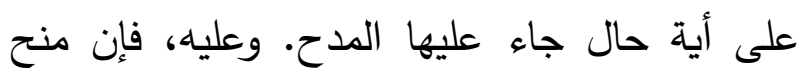

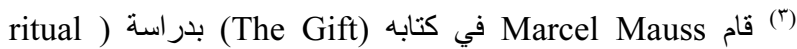
(exchange

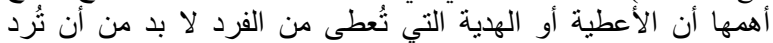

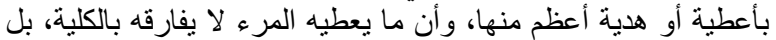

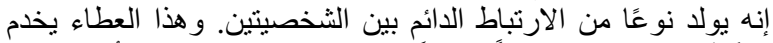

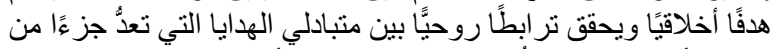

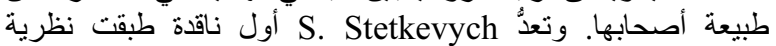
Marcel Mauss

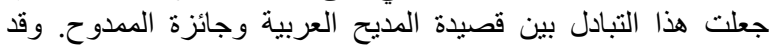

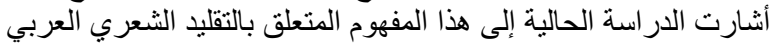

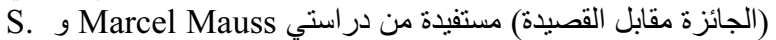

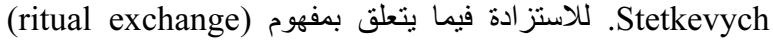
التبادل الطقوسي وطريقة تطبيقه على القصيدة العربية انظر:

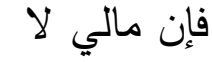
فإن يكن قلّ مـالي بعد وفرته

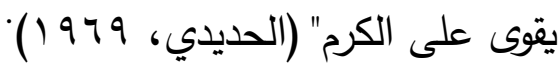

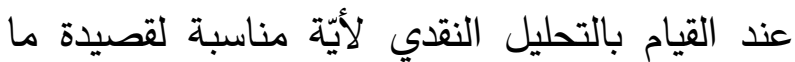
من المستحسن الإفادة من منهج S. Stetkevych في التعامل مع الأخبار المصاحبة للنص الثعري. تنظر

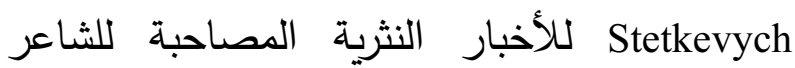
وقصيدته على أنها تقاليد أو أشكال أدبية وليست بحقائق تاريخية (Stetkevych, 2002) (؟). وميزة هذا لهائه المنهج من منظورها أنه "لا يجبرنا على أن نختار

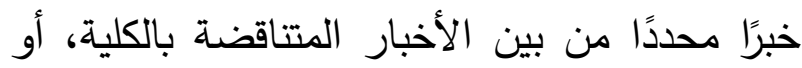

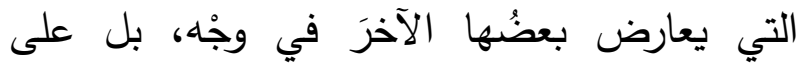
العكس من ذلك فهو يمكننا من أن نقرأ هذه الأخبار

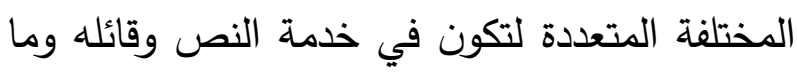
(Stetkevych, يستدعيانه من تقسيرات وتأويلات (2002. كما تئكد Stetkevych على أهمية "تحليل نص الخبر بوصفه نصًا أدبيًا واكتشاف دلالته الرمزية أو التفسيرية في علاقته بالنص الشعري"

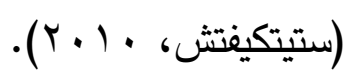

إن الخبر النثري المصاحب لقصيدة حافظ الذي أورده الحديدي أعلاه يتعلق بقضية وثيقة الصلة بمفهوم البيعة الشعرية وطلب الخلافة، ألا وهي

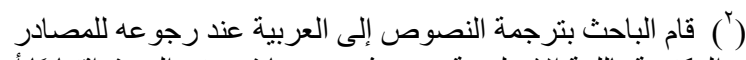
المكتوبة باللغة الإنجليزية، ومن ثم وضعها في في متن البحث القتباسًا أو الو
} 
شكل توسل مراسيمي/بلاطيّ فإن الشاعر لا يقصد

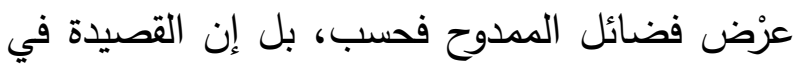
هذه الحال تعلن تحديًا للمدوح يرقى ليتحول إلى فخ أو ابتزاز • وهنا تحديدًا تبرز قوة الثاعر -المتوسل...

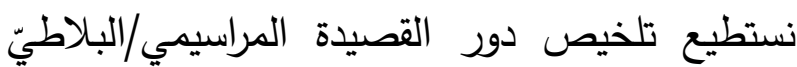

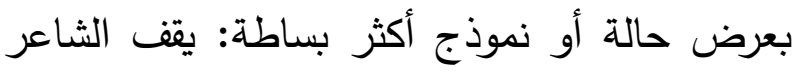

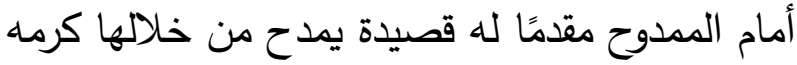

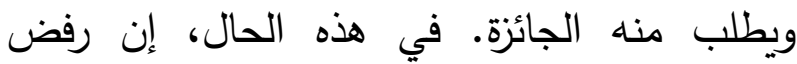
المدوح طلب الثاعر فإنه بالتالي يكون قد رفض ماه تتضمنه القصيدة، وهو وصفه بالكرم، وبناء على ذلك فإن المدوح يُضعف من سلطته المعنوية بوصفه حاكمًا [أو شاعرًا ] شرعيًا. ولكي يثبت منيت

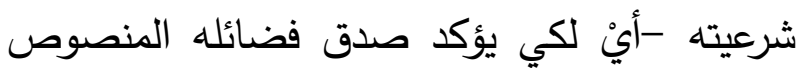
عليها في قصيدة المديح- على الممدوح أن يقبل طلب الثاعر ويلبي حاجته" (Stetkevych, 2002). وبناء على ما سبق يكون البارودي من خلال دفعه

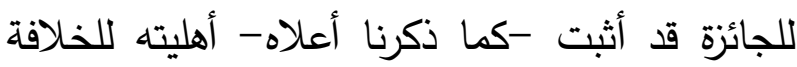
الشعرية من جهة، وبالتالي قدرته على استخلاف

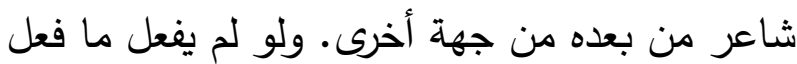
لكان ذلك دليلاً على عدم أحقيته للمكانة التي أثبتها

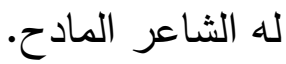

\section{حافظ إبراهيم يعارض داليّة المتنبي:}

من المفاهيم الأدبية المهمة التي تدعُ قضئ لمئية

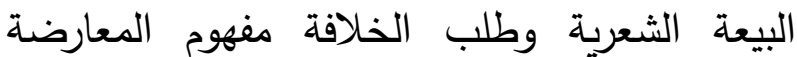
الشعرية. لقد استفاد الشاعر حافظ إبراهيم من قوة ظاهرة المعارضة الشعرية في إعلانه البيعة بالخلافة

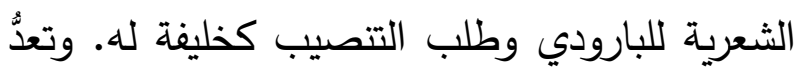
المعارضة الشعرية من التقنيات الفنية المهمة التي لتئي استخدمها شعراء الإحياء -ومنهم حافظ إبراهيم-
الجائزة ما هو إلا إثبات على صدق القصيدة وما فيها من مديح. فالمدوح بإعطائه للجائزة إنما يعطي نفسه ما هو أعظم من ذلك، ألا وهو إثبات الصفات الفاضلة المذكورة في قصيدة المديح لنفسه. وتمشُك البارودي بهذا التقليد الشعري (الجائزة مقابل

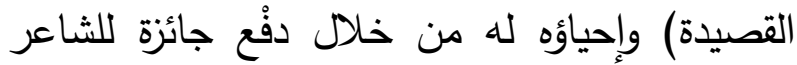
المادح حافظ إبراهيم يدلّ على أمرين، الأول: أهليّة

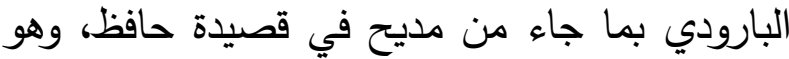
المكانة الشعرية العليا وريادته لمدرسة الإحياء في في الثعر العربي الحديث التي تؤهله للخلافة الشعرية في العصر الحديث لاتصال البارودي بنسب شعري

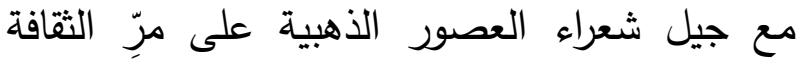
العربية. الثاني: قدرة البارودي -كخليفة للشعر العربي- على استخلاف شاعر مؤهل من بعده؛ ليكمل طريق الإحياء الشعري بالريادة والمحافظة على التراث الثقافي الثعري العربي. وفي الجانب المقابل، فإن البارودي لو لم يحافظ على هذا التقليد

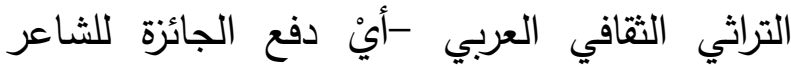
المادح- فإنه سيعلن عن عدم أحقيته للمكانة العليا

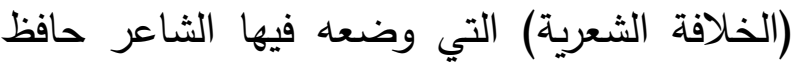
إبراهيم، وما يترتب على فقدانها من تجريد نفسه من

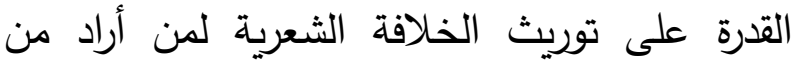
الشعراء من بعده. وفي خبر البارودي مع حافظ إشارة مهمة إلى الدور التفاوضي لقصيدة المديح داخل بلاط المددوح وما يقوم به الثاعر المادح من عملية (نصب فخ لفرانح S. Stetkevych للممدوح) على حد تعبير The Poetic (Stetkevych, 2002) of Islamic Legitimacy): "في تقديم القصيدة على 
كمَا كنتَ قيهُْْ اؤحدا كان اوحَحَا

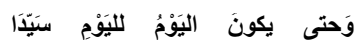

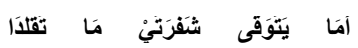

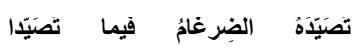

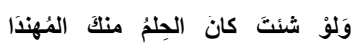
وَمَنَ للتَ بالحُرّ الأي يحفظ اليَّا

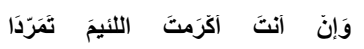
مضرَّ كوضع السيفِ في موضع الندى كما فقتهمْ حالا وَنفسا وَمحتِّا

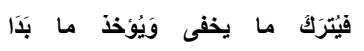

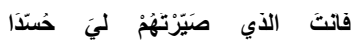
ضرَبَتُ بسَيفِ يَقطعُ الهَامَ مُفْدًَا

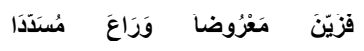
إذا قلتَ شِعرا اصَّبَحَ الدهرُ مُنثِدَا

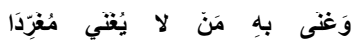

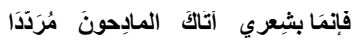

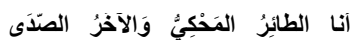

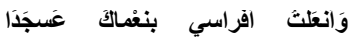

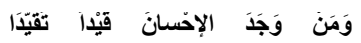

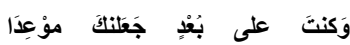
عارض حافظ إبراهيم بقصيدته الداليّة التي تقع في Vr بيتًا قصيدةَ المتتبي الداليّة التي تقع في بـ بيتًا وذلك من خلال اتباع القافية ذاتها وهي الدال المفتوحة، والوزن نفسه وهو بحر الطويل. وقد استخدم حافظ 9 1 كلمة من كلمات القافية الموجودة في قصيدة المتتبي، إما بلفظها أو بإحدى مشتقاتها. كما ضمّن حافظ البيت اب من قصيدته شطرًا من قصيدة المتتبي وهو (إذا قلت شعرًا أصبح الدهر منشدا). وباستخدامه لهذا التضمين يؤكد حافظ على أن قصيدته معارضة شعرية من جهة، كما أنها إعلانٌ لتحدّ أدبي بينه وبين المتتبي من جهة أخرى. قال حافظ إبراهيم مادحًا البارودي ومبايعًا
كوسيلة لبعْث النماذج التراثية العليا لإحياء الثعر العربي الحديث.

قصيدة حافظ إبراهيم الداليّة هي إحدى معارضاته الثعرية لقصائد شعراء العصور الذهبية، فهو يعارض بها داليّة أبي الطيب المتنبي في مدح سيف الدولة الحمداني التي مطلعها: لكل امرىٔ من دهره ما تعودا وعادة سيف الدولة

$$
\text { الطعن في العدا }
$$

قال أبو الطيب المتتبي مادحًا الأمير سيف الدولة

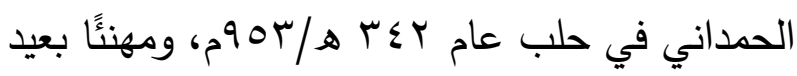
الأضحى (المتتب،

وعادة سيفِ الذوّلهِ الطعن في العدى

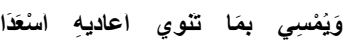

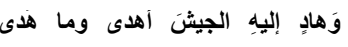

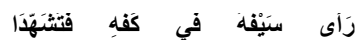

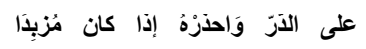

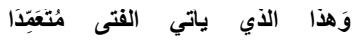

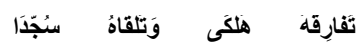

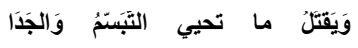

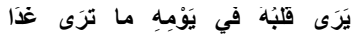
قَلُْ كان قَرْن الثَتمس ماءُ لاوَْرَدا

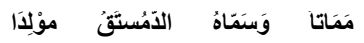

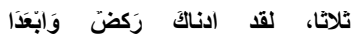

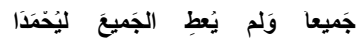

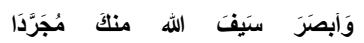

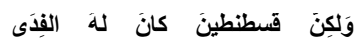

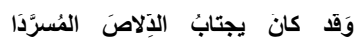
وَما كان يَرْضى مشَيَ اشقرَ اجرَدَا جَريحا وَخلى جَفنه النقعُ ازْمَدَا

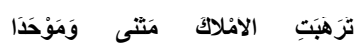

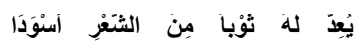

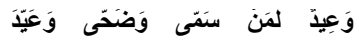

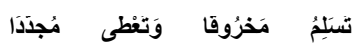

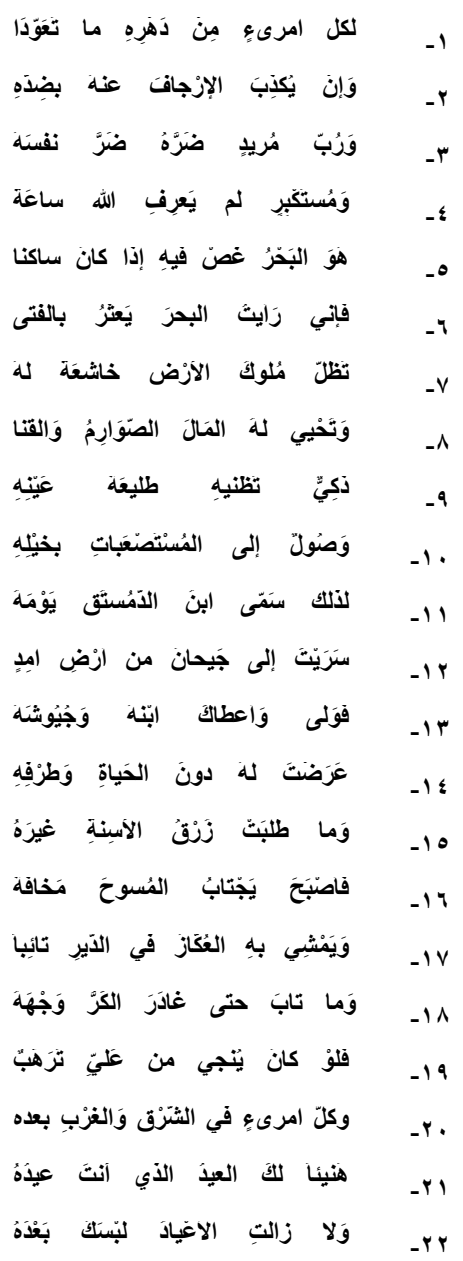




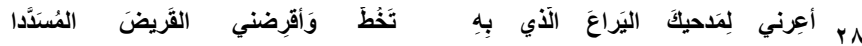

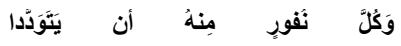

عَلى ضَوْئها أسري وَأققو مَنِ إهتَّى

إذا قلتُ شِعراً أصبَحَ الأهرُ مُننثِدا

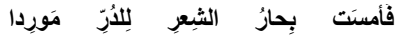

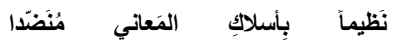

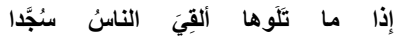

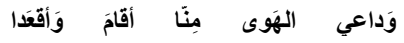

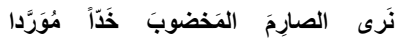

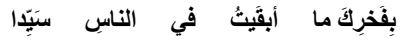

ومن خلال هذه المعارضة الشعرية يقوم الثاعر

حافظ إبراهيم بإعادة كتابة الموروث الثقافي للاستفادة

من قوة قصيدة المتتبي التراثية في دعم قضية معاصرة له، ويكون ذلك عندما تضفي قصيدة

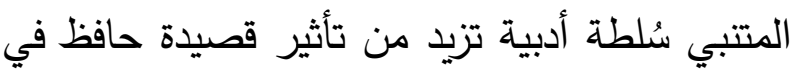
زمنه وبيئته. وطبيعة هذه السلطة تكمن في إثبات النََّبَ الثعري بين حافظ إبراهيم وشعراء العصور

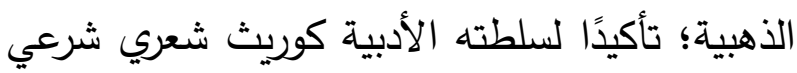
للموروث العربي، وبالتالي أحقيته بالخلافة الشعرية لتهبية التي طلبها من البارودي من خلال كتابة قصيدة مديحه كمعارضة شعرية. وعليه، فإن نَصَّ معارضة حافظ إبراهيم الثعرية "لا يجمع بين المحاكاة والتكرار

مبايعته لأحمد شوفي بسنين عدة حين قال في قصيدة له يمدح أحمد

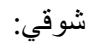

أمير القو افي قد أتيت مبايعا و هذي وفود الثرق قد بايعت

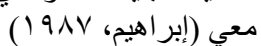

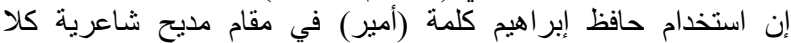

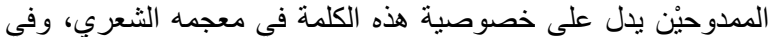

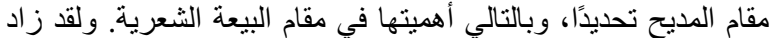

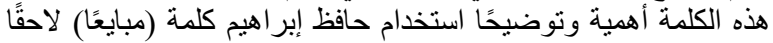
عند مديحه لأحمد شوقي كإضافة توضيحية لعلاقة كلمة (أمير) بالبيعة الثعرية.
بالخلافة الشعرية (إبراهيم، 9AV (1)): (الطويل) فما أثِتِتَ عَيني

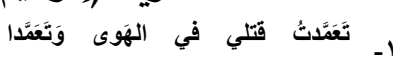

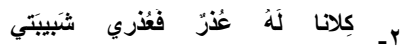

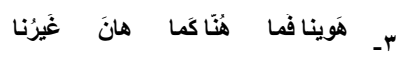

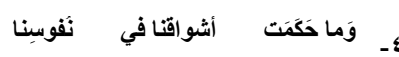

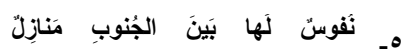

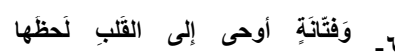

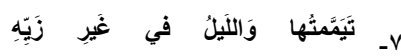

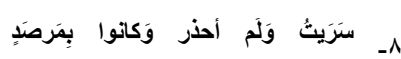
هـ ـ فلمَّا رَأوني أبصَروا المَوتَّ مُقِبلاً

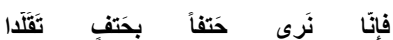

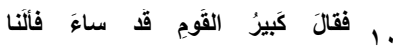

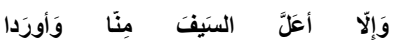
شَبَا صارِمي عَنهُم وَقَ كانَ مُفْدَا

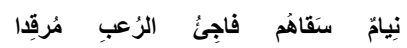

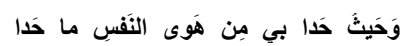

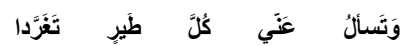
على البَّرِ سِتراً حالِّت اللونِ أسوَدا

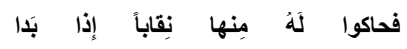
وَلْم تَثْنِي عَن مَوَعِدي خَشَيَة الرَدى

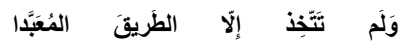

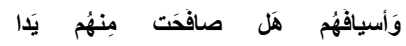

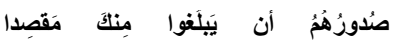

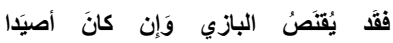

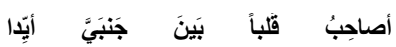

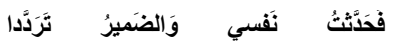

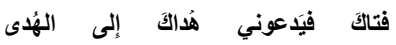

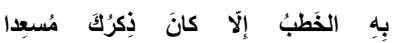

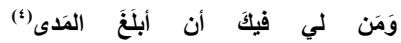

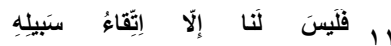

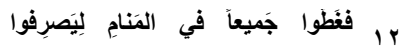

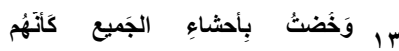
عا وَرُحتُ إلى حَيثُ المُنى تَبَعَثُ المُنى

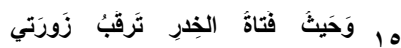

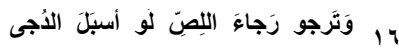

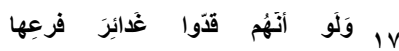

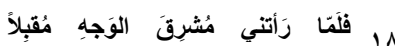

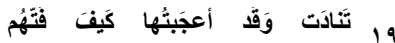

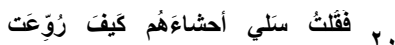

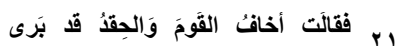

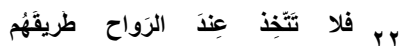

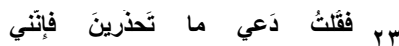

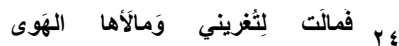

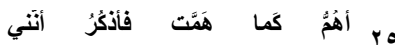

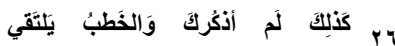
أميرَ القَوافي إن لي مُستَهامَة بِمَدَح rV

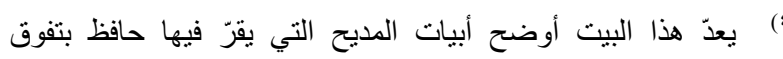
البارودي على غيره من الثعراء، ونربعه على قمة الهرم الأدبي في لئي

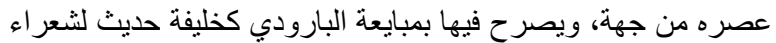
الثقافة العربية في عصور ها الذهبية من جهة أخرى. ومبايعة حافظ إنظ

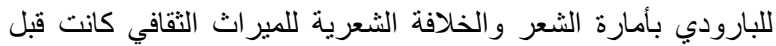


كذلك في مقام القصيدة ومناسبتها. فالثاعر المتمكّن يقوم -قاصدًا- بتوسيع غرض معارضته الشعرية واستخدامها في قضية عظمى تكون مرتبطة بتجربته الشعرية. فحافظ إبراهيم يستقيد من القوة التراثية

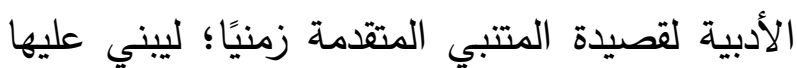
خلفية ثقافية فكرية يتكئ عليها كقوة انطلاق أولى في إنشاء معارضته، ومن ثم يحوّل طاقة النص الأصلي الإيجابية إلى عالمه الخاص وقضايا أمته، وتحديدًا قضية إحياء الشعر العربي. وعليه، يكون حافظ بتوسيع غرض داليّته لترتبط بقضية مفصلية في حياة

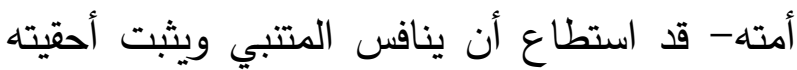
بالخلافة الشعرية(0). ولكي يؤكد حافظ أحقيته وأهليته ليكون خليفة للبارودي فإنه يؤدي من خلال معارضته الشعرية عدة أدوار متتوعة، لكنها في الوقت ذاته مترابطة منسجمة، وهي أدوار كان البارودي قد قام بها من فن إنهان قبل في مشروعه الإحيائي. ومن هذه الأدوار : إحياء

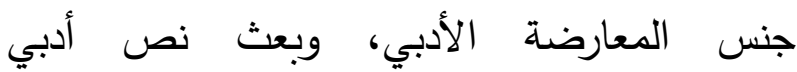
كلاسيكي/تقليدي مهم ومؤثر؛ لتعريف المتلقي بأنموذج أدبي عالٍ من الموروث الأدبي، وتثجيعه على الإعجاب بإزْثه الأدبي العربي واحترامه. ومنها

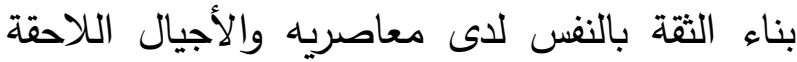
في مقدرتهم على المساهمة في إعادة بناء موروثهم الثقافي عن طريق منافسة نماذجه العليا ومحاولة

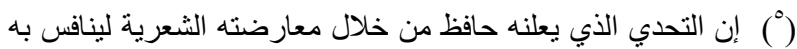

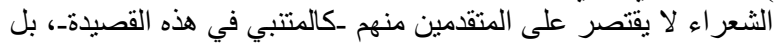
يتجاوزه ليشمل معاصريه كذلألك.
لنص أنموذج واهب للسلطة فحسب، بل إنه يبدّل هذا

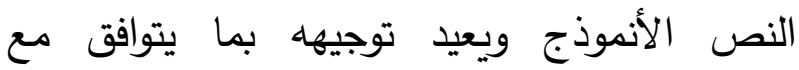
اهتمامات الثاعر المعاصر وأهدافه" .(Stetkevych, 2010) إن اختيار حافظ إبراهيم أن يمدح البارودي بقصيدة تُعدّ معارضة شعرية لقصيدة شاعرِ عظيم من شعراء العصر الذهبي -حال كونه يمدح أميرًا-

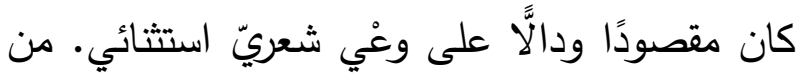
خلال قصيدته الداليّة يعلن حافظ إبراهيم عن متابعته للبارودي في جنس المعارضة الثعرية؛ لأنها تعدّ

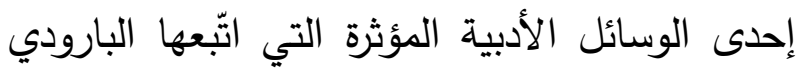
لإحياء الثعر العربي، ومتابعته في معارضة المتنبي تحديدًا؛ لأنه يُعدّ أكثر شاعر عارضه البارودي

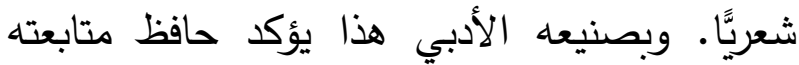
لقدوته البارودي، ومحاولته الحثيثة لاستحقاق الخلافة

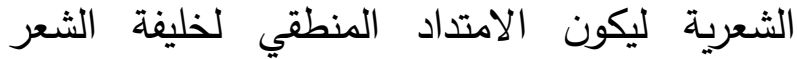
العربي ورائد مدرسة الإحياء في العصر الحديث. أضف إلى ذلك كوْن المعارضة الشعرية وسيلة لإثثات المنافسة؛ وهو الأمر الذي يسعى حافظ لتأكيده أمام قدوته البارودي لإثبات جدارته الثعرية، فحافظ يريد إثبات قدرته على مقارعة كبار الشعراء

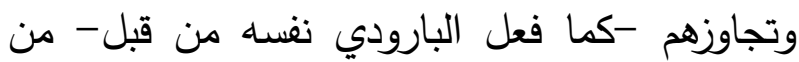
خلال معارضاته الشعرية لشعراء العصور العربية

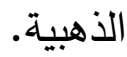
إن التنافس في المعارضة الشعرية لا يكون في جودة القصيدة وعناصرها الثعرية فحسب، بل يكون 
بلاط الحكام، وهذا الارتباط يجعلها -بعيدًا عن كونها مجرد قصيدة تصويرية وصفية بحتة، أو إجرائية توجيهية، أو متملقة بشكل استجدائي تذلّلي كما زعم بهوني بعض النقاد- تؤدي دورًا فاعلًا حاسمًا في التبادلات الطقوسية، والمفاوضات ذذات الحساسية العالية، وصنُع الأساطير في البلاط العربي الإسلامي" العيات (Stetkevych, 2002). وبناء على هذا المفهوم، فإن قصيدة المديح التي أناقشها في هذه الدراسة ليست

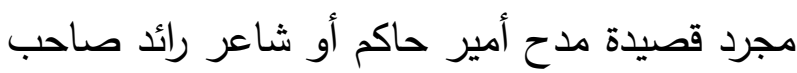
مشروع نهضوي يقصد منها الثاعر المقابل المادي

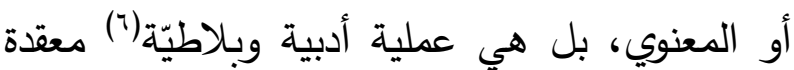
تتعقد عليها نية قائلها في الدخول في عملية تفاوض

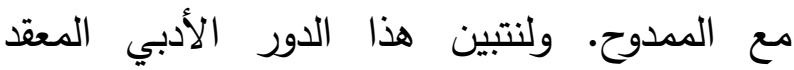
لقصيدتي المتنبي وحافظ إبراهيم علينا أن نتطرق إلى الى وغْي الثاعرين بالأغراض الشعرية لقصيدتيهما والاستفادة من أقسامهما بما يخدم غرض كل واحد

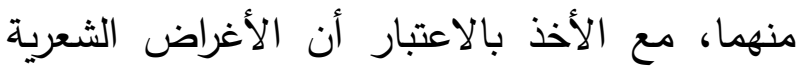
ليست على مستوى واحد من المعاني وما يتعلق بها من دلالات، بل تحتوي على مستويات متعددة يخلقها الثاعر الجيد ليسخرها لغرضه الرئيس من قصيدته

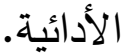

اختار أبو الطيب المتنبي لداليّته التقسيم الأُحاديّ إذ تقعُ قصيدته في قسم واحد هو المديح. ويمكن

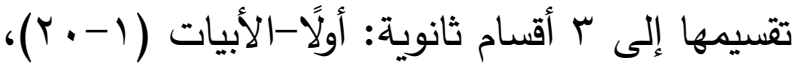

(") كلمة (بلاطيّ) نسبة إلى (بلاط) الحاكم أو من في حكمه كالأمير

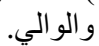

تجاوز أثرها وتطبيقها على واقعهم. ومن ذلك تأسيس نسب شعري بين النص الكلاسيكي/التقليدي ونص

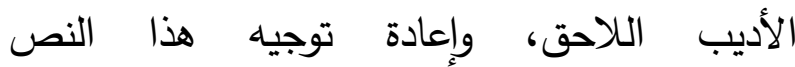
الكلاسيكي/التقليدي ليخدم رؤيته الفلسفية التي تعبر بوضوح عن الاهتمامات والمشاكل المعاصرة له.

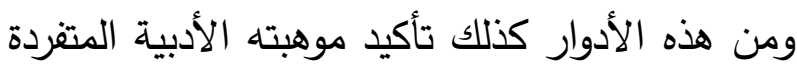
ومقدرته على منافسة الأدباء الكلاسيكيين/التقليديين وتجاوزهم، وتأكيد -بالتالي- كونه الوريث الثرعي للموروث الأدبي العربي. وبناء على ما سبق تستطيع الدراسة أن تثبت قدرة الثاعر حافظ إبراهيم على الاستفادة من قوة ظاهرة المعارضة الشعرية كوسيلة أدبية لإعلان البيعة بالخلافة الشعرية للبارودي من جهة، وطلب التتصيب كخليفة له من جهة أخرى. الوغْي بإمكانات بنية القصيدة : إن دوز قصيدة المديح في عملية المفاوضات التي تدور داخل بلاط الممدوح غير مقتصر على مفهوم

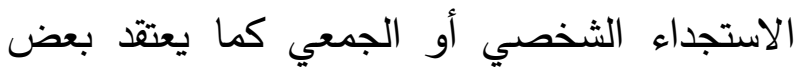
الباحثين، بل إنه يتجاوز هذا الأمر ليصبح أكثر S. تعقيدًا داخل الكيان الهرمي للمجتمع. تقول Stetkevych التقليدية/الكلاسيكية -التي تعدّ قصيدة احتفائية

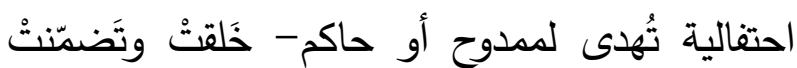
بشكل ترميزي ورَوّجتْ بشكل واسع لأسطورة

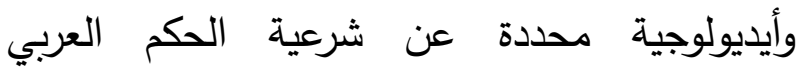
الإسلامي...وقصيدة المديح مرتبطة بشكل وثيق

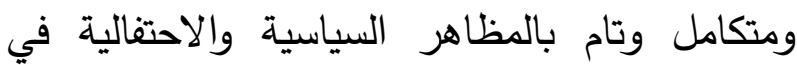


10-0)(9)، ب- الغزل الصريح الذي يستطرد فيه الثاعر واصفًا مغامرة عاطفية جريئة جمعته

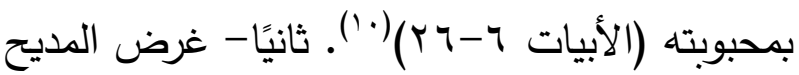
(الأبيات لrV ختامًا ما وراء شعري (Metapoetic closure) يركّز فيه حافظ إبراهيم على مدح شاعرية البارودي مؤكدًا تفرّده الشعريّ ومنزلته الشعريّة العليا التي تفوق شعراء عصره كلهم (الأبيات ؟Y-Y

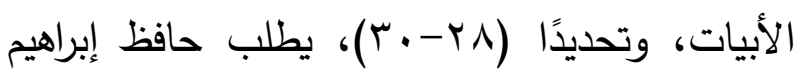

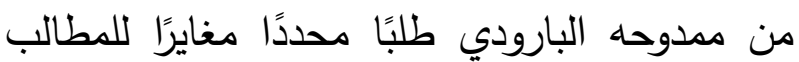
التي تصدر عادة من الشعراء المادحين كطلب

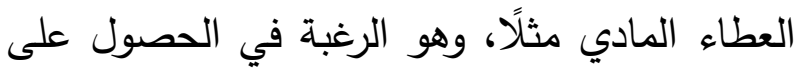
المقومات التي جعلت الممدوح يتقلد المكانة الشعرية العليا في زمنه (أميرَ القوافي)؛ ليتمكن الثاعر المادح من منافسة شعراء العصور الذهبية المتصلين بهما بنسب شعري (البيت آس). فهذه الأبيات تجمع مناهيه ما بين الاعتراف بمكانة الممدوح الثعرية ورغبة

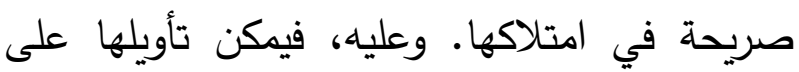
أنها مبايعة شعرية من جهة وطلب الخلافة من جهة

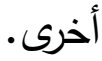

ومع أن كلا الثاعرين قد استخدم في قصيدته ختامًا ما وراء شعري يمدح فيه شعره -كما هي

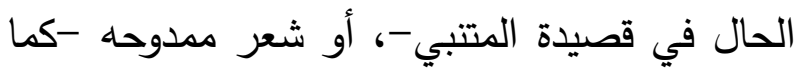
هي الحال في قصيدة حافظ- إلا أن غرض كل فئل

(9) هذا النوع من الغزل يشبه الغزل العذري الذي انشتهر به شعراء بني عذرة من أبناء بادية نجد في العصر الأموي.

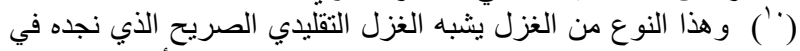
قصائد متعددة لثعر اء معروفين كامرئ القيس و عمر بن أبي ربيعة.
وفيها يمدح المتنبي سيفت الدولة بوصفه القائد الذي

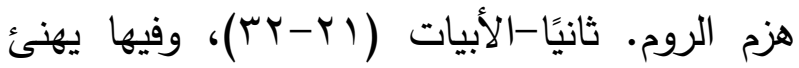
أبو الطيب المتنبي الأميرَ سيف الدولة الحمداني بعيد الأضحى مادحًا إياه بالتفرد بين الناس، ومؤكدًا

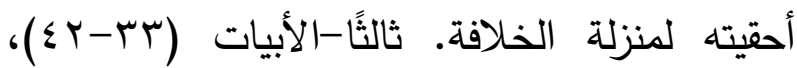
وهي ختام ما وراء شعري (Metapoetic closure) يفتخر فيه المتنبي بمكانته الشعرية العليا التي لا لاه تقارن بغيره من الشعراء من جهة، كما يعلن ولاءه

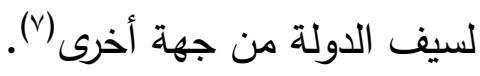
وفي المقابل نجد أن الشاعر حافظ إيراهيم قد اختار لداليّته تقسيمًا ثنائيًا (^)، فوضع فئد قصيدته في

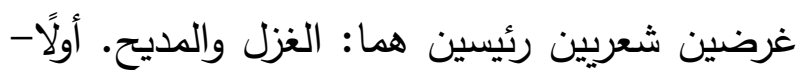

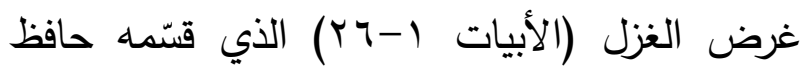
إلى قسمين: ا- الغزل العفيف الذي يربط فيه الثاعر بين القيم الأخلاقية ومشاعر الحب (الأبيات

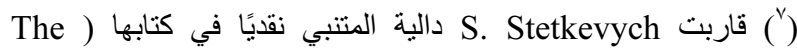
Poetic of Islamic Legitimacy

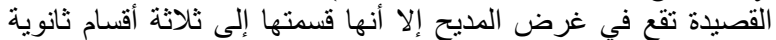

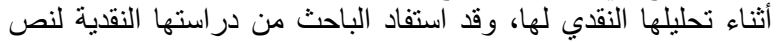

الكتنبي. انظر: (Stetkevych, 2002) من الدراسات التي تناولت داليّة الـتنبي:

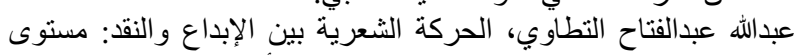

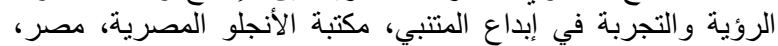

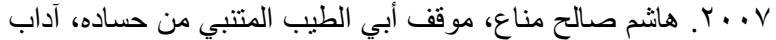

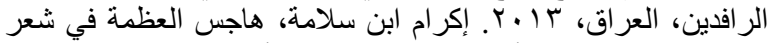

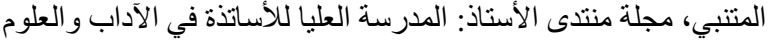

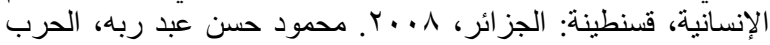

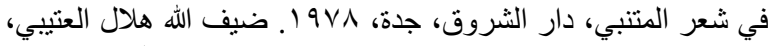

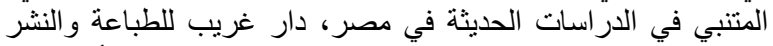

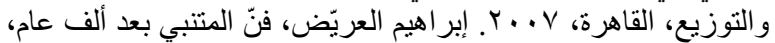

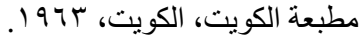

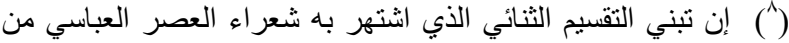

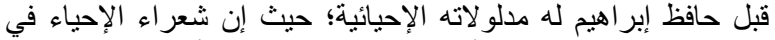

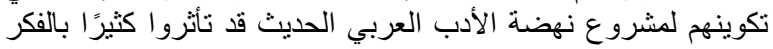
الثقافي للعصر العباسي ودور شعر ائه في بلورتها. 
هذين الغرضين تحديدًا لمعرفته بشاعريّة البارودي.

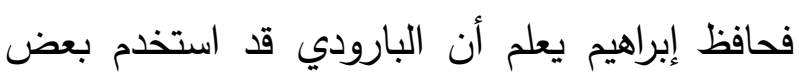
ثيمات غرض النسيب بما فيها من موتيفات استخدامًا رمزيًا له علاقة بواقع الشاعر، ومن ذلك استخدام موتيف (الحبيبة) لتصبح في كثير من قصائده قابلة للتأويل لأن تصبح رمزًا للثقافة العربية الإسلامية

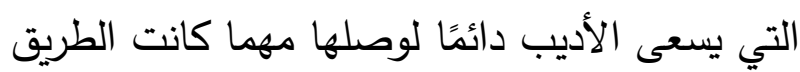

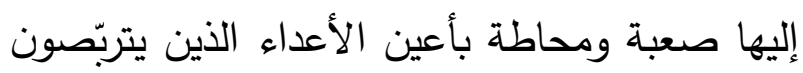

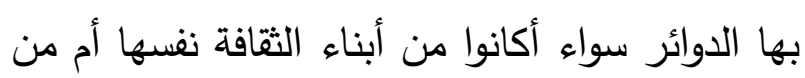

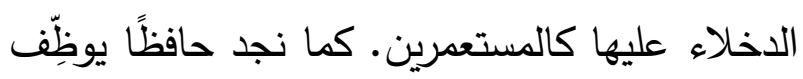
كذلك غرض الحماسة/الفخر في قصيدته؛ لأن البارودي في مواطن كثيرة في ديوانه قد وظّف الفخرَ

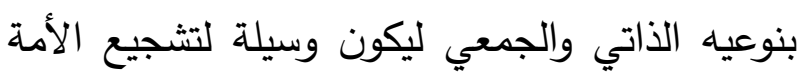

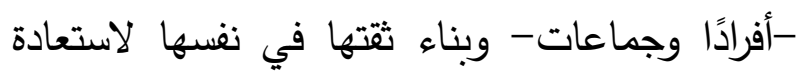

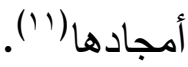

وقد تميّز كلٌّ من المتنبي وحافظ بالقدرة على التمهيد الشعري لغرضيهما؛ فعلى مشارف نهاية القصيدة مهُّةَ المتنبي إلى مديح نفسه، وتحديدًا شعره، بتقديم مديح خاص لسيف الدولة يتعلق بحكمته ورأيه

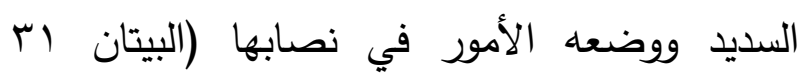
و rץ)، ومن ثم طلب من ممدوحه -مستغلًّ دلالات

(") ومثال هذا التوظيف الفني لغرضين النسيب والفخر ما نجده في

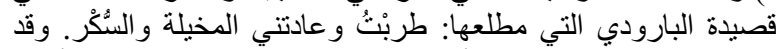

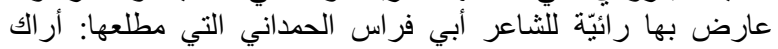

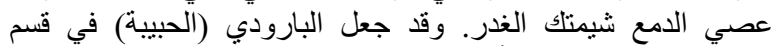

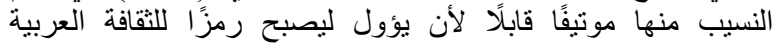

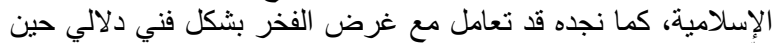

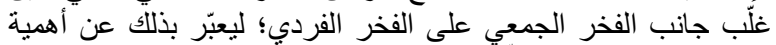

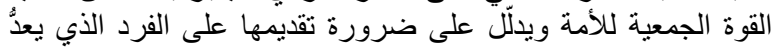

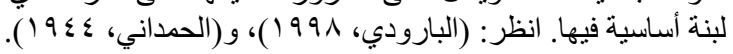

منهما يختلف. فبينما جاء ختام أبيات المتتبي مؤكدًا تميزه داخل بلاط الأمير وتقوقه على أقرانه من لناء الشعراء الذين ينافسونه ليضمن الحفاظ على مكانته عند ممدوحه، جاء ختام أبيات حافظ مؤكدًا تميز مددوحه البارودي وتفرّده على نطاق أوسع يشمل منداء

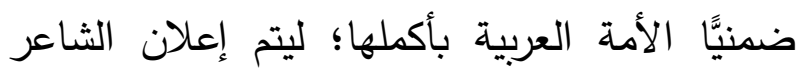

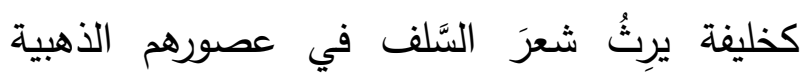

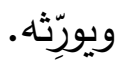

في آخر قسم الغزل (البيتان هr و وب اللذان يعدّان بيتي الانتقال أو التخلص في القصيدة) يشير حافظ

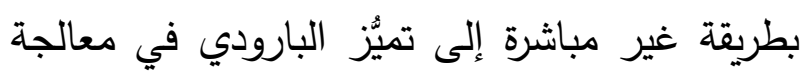

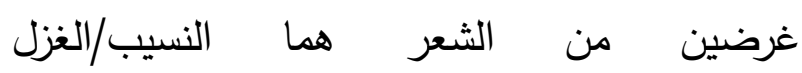
والحماسة/الفخر ، وذلك حين يؤكد تأثره الإيجابي بقدوته البارودي في حالتي الحب (البيت ب0 بالبره والحرب (البيت بr). وفي قسم المديح يختم حافظ

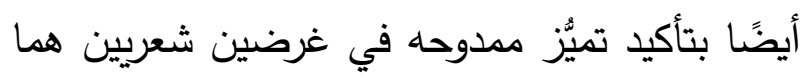

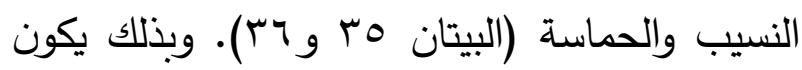
حافظ قد ربط بين غرضي قصيدته، كما أكّد بطريقة فنية- أن القسم الأول منها ما هو إلا تمهيد لقسمها الثاني، وذلك عندما ختم قسم الغزل بتأكيد شاعرية البارودي ضمنيّاً في غرضي الني النسيب والحماسة تحديدًا، وختم قسم المديح بتأكيد شاعرية البارودي صراحةً في الغرضين نفسيهما كذلك. وبما أن البارودي قد استغل شعره عامة لغرونين

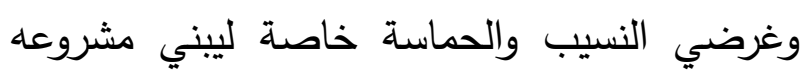
الإحيائي، فإننا نجد حافظًا يركّز في قصيدته على ولى لئي 
"المديح نادرًا ما يظهر دون تعزيز لحوافز بعينها.

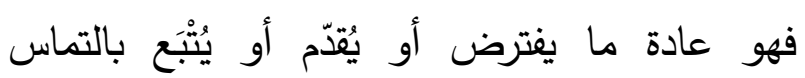
الثاعر تحقيق رجاء أو شفاعة أو معروف؛ سواء كان اعتذارًا، أو مكانة متميزة في البلاط، أو تعويضًا

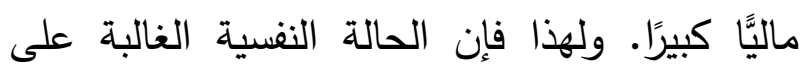
المديح هي حالة التوقع، حالة الأمل" (ستيتكيفتش،

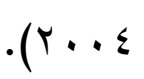

بلاغة التلاعب بالتقليد الشعري القديم:

إن التقليد الثعري يقضي بأن تكون القصيدة التقليدية الكلاسيكية مقسمة إلى ثلاثة أقسام كما لتصني يتضح غالبًا في القصيدة الجاهلية، أو إلى قسمين كما يتضح غالبًا في القصيدة العباسية('ا'). والقصائد التي كانت تثذُّ عن هذين الثكلين يكون لها في لهاني الأغلب مبرراتها التي تتوافق مع حال الثاعر وغرضها(r'). كما يقضي التقليدُ الشعري كذلك بألّا

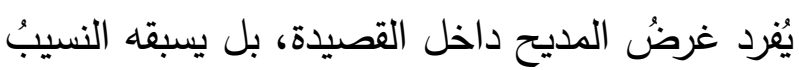

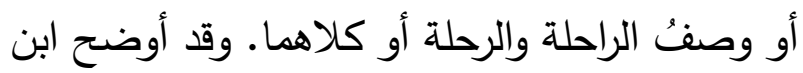

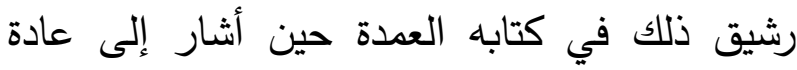
الثعراء في افتتاح قصائدهم بالنسيب ومذاهبهم فيه

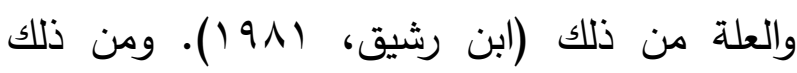

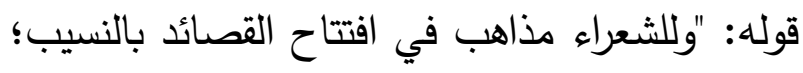
لما فيه من عطف القلوب، واستدعاء القبول بحسب ولب فئب ما في الطباع من حب الغزل، والميل إلى اللهو

(r) لتوضيح غلبة التقسيمين الثلاثي والثنائي على القصيدة التقليدية القديمة انظر : (Stetkevych, 2002)

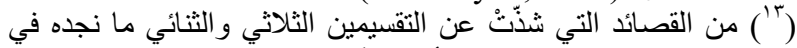

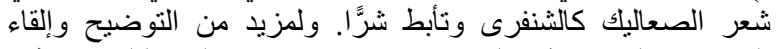

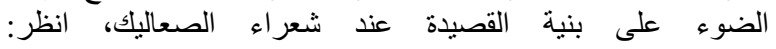
(Stetkevych, 1993)
أبيات مديحه- أن يضعه في مكان عليّ يفوق قرناءه

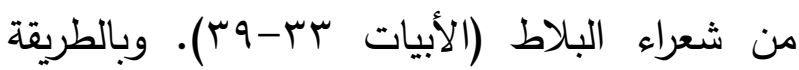
ذاتها -مع اختلاف الغرض الشعري- نجد الثاعر حافظ إبراهيم قد بدأ القصيدة بغرض الغزل المتضمن مديحًا للبارودي؛ ليحمّله مديحًا لذاته يؤهله للخلافة

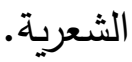

وأبيات المديح في كلتا القصيدتين يمكن أن تؤوَّل لتصبح مبايعة من الثاعر لمددوحه، إلا أن مبايعة المتنبي لسيف الدولة جاءت بناء لما رآه في آلي

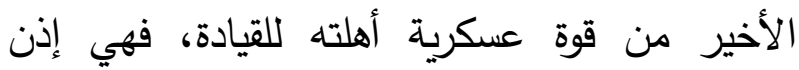
مبايعة سياسية، ومبايعة حافظ للبارودي جاءت بناء على ما رآه في ممدوحه من قوة شعرية استثنائية

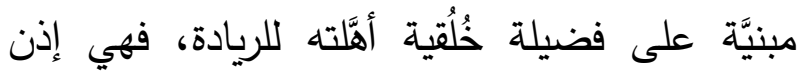
مبايعة أدبية. وبناء على طبيعة البيعتين نجد اختلاف مطلب الثاعرين، فقد قام المتنبي بطلب

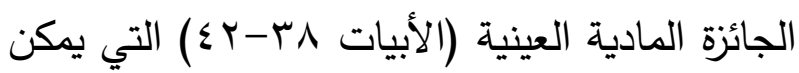
أن تؤَّل بطلب الولاية أو الأمارة، أيْ أن المتنبي قد الدان طلب السلطة السياسية. في المقابل نجد أن حافظًا

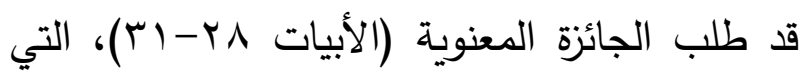
يمكن أن تؤَّل بطلب الاعتراف بمكانته الشعرية وذلك بإدراجه في النسب الشعري لشعراء العصور الذهبية عن طريق تتصيبه خليفة للبارودي، أيْ أن إن فئن

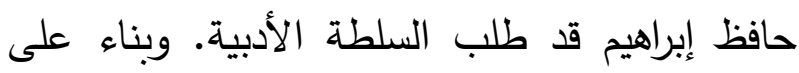
ذلك، فقد ناسبت البيعتان المطلبين؛ فمن كانت بيعته سياسية كان مطلبه سياسيًا، ومن كانت بيعته أدبية

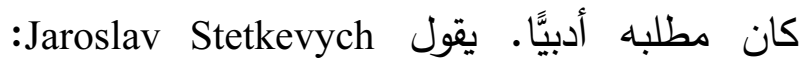


ويقضي التقليد الثعري أيضًا بأن يكون قسُ المديح أكثرَ طولًا من الأقسام التي تسبقه، وتحديدًا

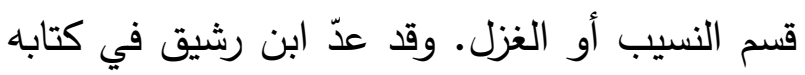
العدة كثرة أبيات النسيب في مقابل أبيات المديح عيًًا حين قال: "ومن عيوب هذا الباب أن يكون النسيب كثيرًا والمدح قليلًا" (ابن رشيق، و (919 1). وقال في موضع آخر: "ومن عيوب هذا الباب أن

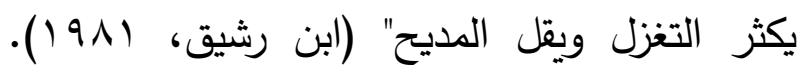
وفي تأييد هذا المعنى أورد ابن رشيق خبر أحد الثعراء المادحين لنصر بن سيّار فقال: "يُحكى عن لن

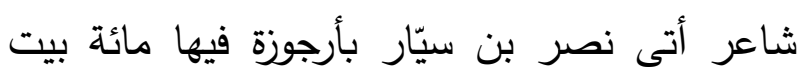

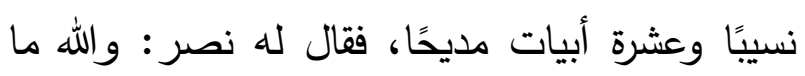

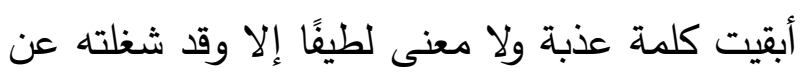

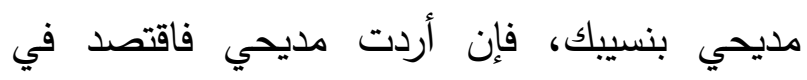
النسيب، فغدا عليه فأنشده:

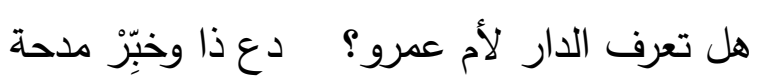
في نصر

فقال نصر: لا هذا ولا ذاك، ولكن بين الأمرين"

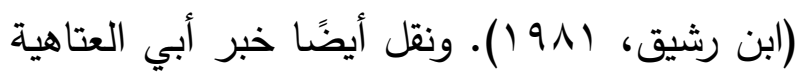

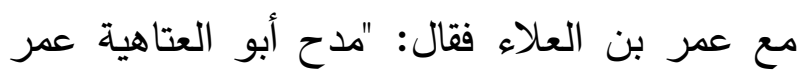

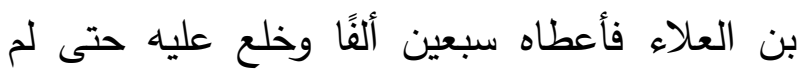

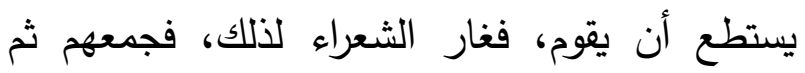

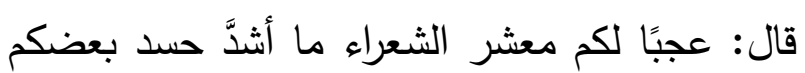
لبعض، إن أحدكم يأتينا ليمدحنا فينسب في قصئ لصيدته

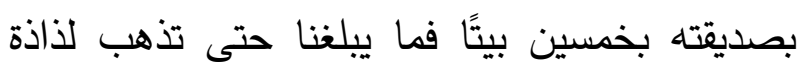

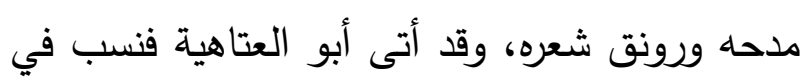

والنساء، وإن ذلك استدراج إلى ما بعده" (ابن رشيق،

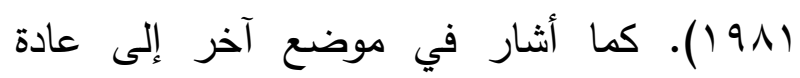
الشعراء في ذكر الراحلة والرحلة وما فيها من مشقة إنة

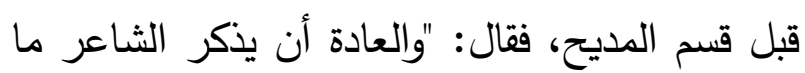
قطع من المفاوز، وما أنضى من الركائب، وما تجشم من هول الليل وسهره، وطول النهار وهجيره، وقلة الماء وغؤوره، ثم يخرج إلى مدح المقلى ونصود؛

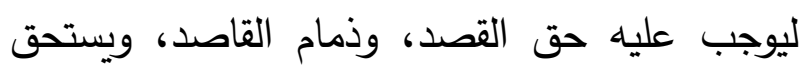

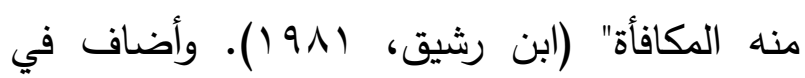
موضع آخر : "وليس من عادة الثعراء أن يقدموا قبل الرثاء نسيًاً كما يصنعون ذلك في المدح ولهن والهجاء"

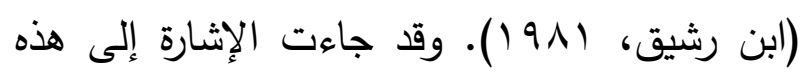

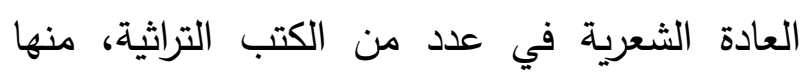
كتاب (خزانة الأدب) للبغدادي الذي قال معقبًا على عنى

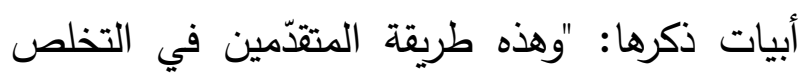
إلى المديح وهو أنهج يصفون الفيافي وقطعها بسير

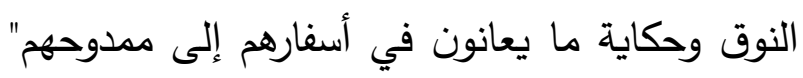

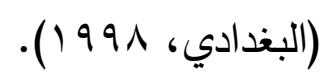
وقد عاب ابن رشيق فعلَ الشعراء الذين يُلغون قسم الذّاء النسيب من قصائدهم أو يختصرونه اختصارًا مخلًّا حين قال: " ومن الشعراء من لا يجعل لكلامه بسطًا من النسيب، بل يهجم على ما يريده مكافحة، وتتاوله

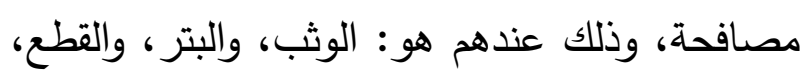

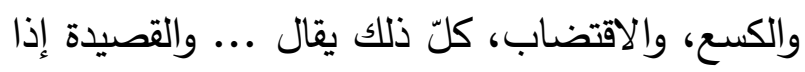
كانت على تلك الحال بتراء كالخطبة البتراء والقطعاء" (ابن رشيق، (919 )). 
المديح تشبيبًا، ووصف إبل، وركوب فلواتٍ، ونحو ذلك، فكأن زهيرًا همّ بذلك، ثم قال لنفسه: دوعْ الذي وتي

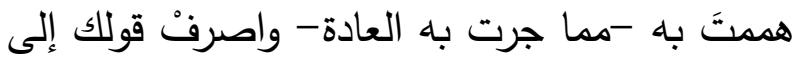

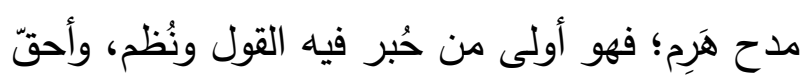

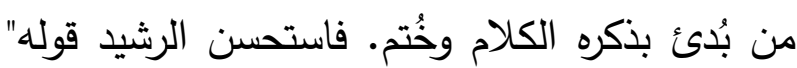

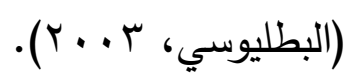
وعليه، فإن صنيع المتنبي هذا يدلّ على رغبته في

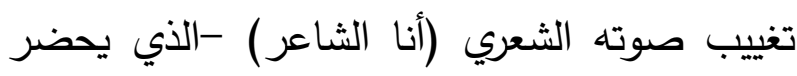
غالًَا من خلال النسيب أو الغزل في التقليد الشعري القديم- كإستراتيجية شعرية أولى. فالمتنبي يشرع مباشرة في المديح؛ ليؤكد المبالغة في إظهار تثرّد مددوحه والإعلاء من مكانته وتركيز دائرة الرؤية

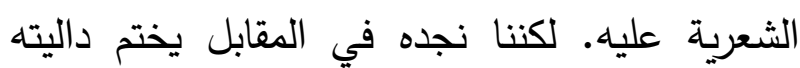
بختام ما وراء شعري يمدح من خلاله شاعريته المتفردة ويمزجه بمديحه لسيف الدولة؛ ليؤكد بذلك من فئك حضور صوته الشعري. هذا الحضور المتأخر لصوت الثاعر يعدّ تغييرًا في النّّق الشعري، لكنه هُّن في الوقت نفسه تغيير مبني وفُق مُخطط شعري يمكن تأويله على أنه نوع من التوسّل المبالغ فيه. ويظهر هذا التوسّل تحديدًا عند استخدام المتنبي من تلني لفعلي الأمر التاليين: (أجزْني، دعُ).

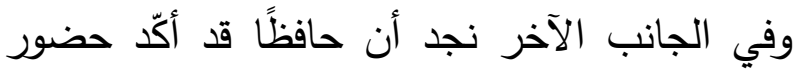
صوته الشعري (أنا الشاعر) بشكل واضح منذ بداية القصيدة؛ وذلك من خلال حضور غرض الغزل في

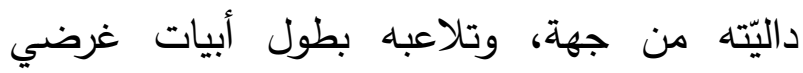
القصيدة من جهة أخرى. ولم يكتف حافظ بذلك، بل ونل بطول
أبيات يسيرة" (ابن رشيق، (91 1).

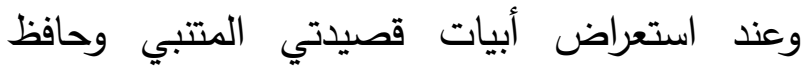
نلاحظ أن كلا الثاعرين قد تلاعب بالتقليد الشعري للقصيدة العربية بما يتوافق مع غرضهه من المديح.

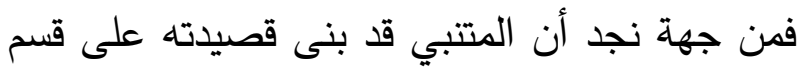

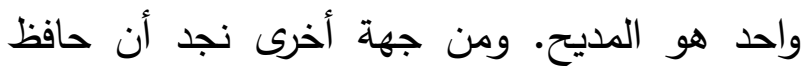
إبراهيم قد أطال قسم الغزل (דب بيتًا) في مقابل قسم المديح (11 بيتًا) إطالة واضحة، بالإضافة إلى لئى استخدام الغزل بنوعيه الصريح والعذري داخل الغرض الواحد. وهذا الفعل الشعري عند الثاعرين غير مألوف في التقليد الشعري للقصيدة العربية.

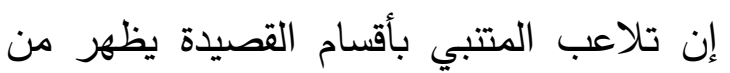

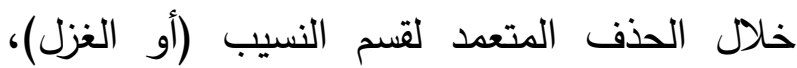
وإنشائها على غرض واحد هو المديح. وقد نقلنا أعلاه تأكيد ابن رشيق عادة الشعراء في افتئاح قصائدهم بالنسيب وذكر الرحلة، وانتقاده للشعراء الذين يلغون قسم النسيب أو يختصرونه، إلا أنه قد ورد عن بعض الشعراء تجاهلهم لهذه العادة الشعرية

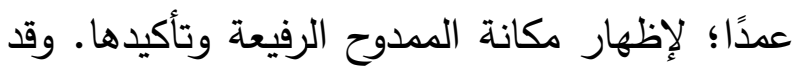
أورد البطليوسي قصة تؤيّّ ذلك حين قال: "قد روي: أن هارون الرشيد، قال للمفضّل بن محمد: كيف بدأ

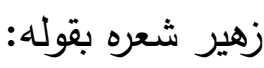

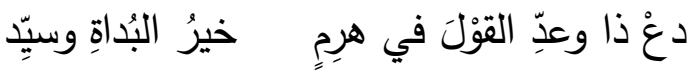
الحضرِ

ولم يتقدم قبل ذلك شيء ينصرف إليه؟ فقال المفضّل: قد جرتُ عادة الشعراء بأن يقدّموا قبل 
الآخر لإعلاء شأن الذات -باختلاف طريقة كل واحد منهما وغرضد- إلا أن الفرق الواضح ييرز في مهارة حافظ حين يحرص على دمج شخصيته الشعرية بشخصية البارودي في القصيدة بأكملها، وكأن حضور البارودي في أبيات المديح ما هو إلا لهائ تضخيم لصوت حافظ الشعري وترويج لمكانته وتثبيت لها. فحافظ يدرك أن الزيادة في محاكاة البارودي تجعله أقرب إلى تحقيق هدفه؛ لذا نجده يؤكد هذا الاندماج بين الشخصيتين في القصيدة بأكملها ليبرر استحقاقه للخلافة الثعرية من بعده.

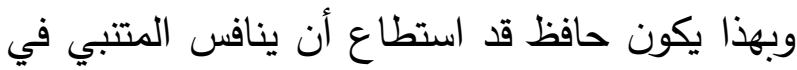

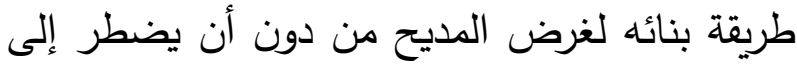
إلغاء صوته الشعري أو تغييبه مؤقتًا لدمْجه لاحقًا في ختام القصيدة كما فعل المتنب. إن قيام كل من المتنبي وحافظ إبراهيم بهذا التلاعب المبان الشعري -سواء أكان بأغراض القصيدة من حيث الغياب أو الحضور، أم باختلاف تتاسب عداء الأبيات في كل غرض، أم بدمج نوعين مختلفين ينتميان لغرض واحد- يدل على مدى معرفتهما بالتقاليد الشعرية ومهارتهما في محاولة التلاعب بها وإخضاعها لأغراضهما الشخصية التي تخدم هدفيهما من وراء قصيدتيهما. تقول S. Stetkevych: "نستطيع أن نقترح أن الشعراء لديهم حس بالثكل، أو أنهح يمتلكون لغة تعبيرية عن الثكل تسمح لهم بالتلاعب بأقسام القصيدة ومقاطعها من أجل تحقيق تأثيرات جمالية ودلالية محددة ومتتوعة" (ستيتكيفتش،
نجد أنه قد أصرّ على إبقاء صوته الشعري -وإن كان بدرجة أقلّ وضوحًا- في قسم المديح. ويتأكد هذا الحضور لصوت الثاعر حينما يطلب حافظ من لين البارودي أن يساعده على استكمال القوة الشعرية

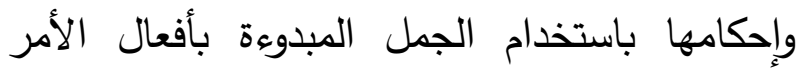

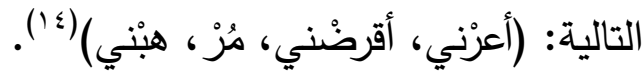
إن طريقة المتنبي في التعامل مع صوته الثعري

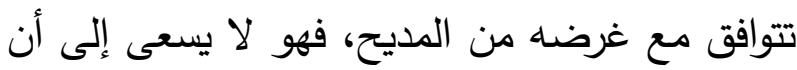

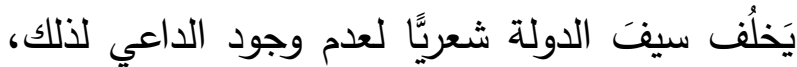

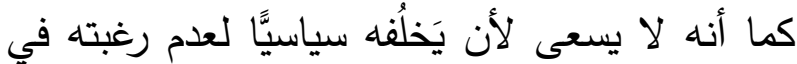
منافسة الأمير وأسرته، وإنما يسعى لإلى لهـ لستبقائه

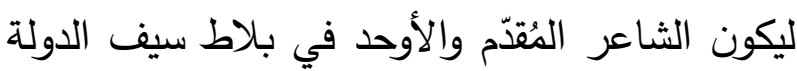

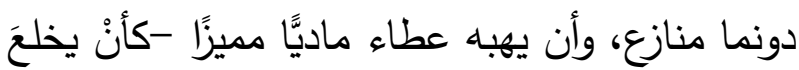
عليه أمارة أو ولاية- يحفظ به مكانته بين أقرانه ويثبتها في دولته. وفي المقابل نجد أن إصرار حافظ على إظهار صوته منذ بداية القصيدة إلى منتهاها في قسمي الغزل والمديح يدلّ على إلحاحه المتواصل في إظهار قوة شاعريته وتأكيدها، وبالتالي إظهار لهارل رغبته القوية في الخلافة الشعرية. فظهور صوت المتتبي متأخرًا بعد استكمال المديح ومبالغته فيه جاء

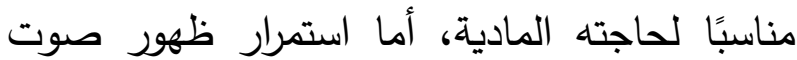
حافظ في ثنايا قصيدته فقد جاء مناسبًا لحاجته المعنوية وهي طلب الخلافة الثعرية. ومع أن كلا الثاعرين قد استطاع أن يستغل مديح (') إن في استخدام أفعال الأمر من قبل الثاعرين دلالة على تقصصهما الدور (الثُاعر المتوسل). 
• • • (Y). وبناء على ما سبق، تثبت الدراسة أن إلى هذا أعلاه.

استطاع حافظ إبراهيم أن يجعل قصيدته بأكملها - إهداه مع كونها مبنية على غرضين شعريين هما الغزل والمديح- في مدح البارودي. وهذا المدح يفضي في في فئي

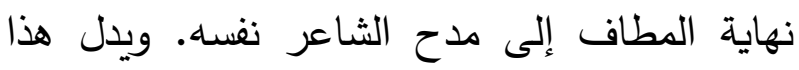
الفعل على وعي حافظ إبراهيم الاستثنائي بدور

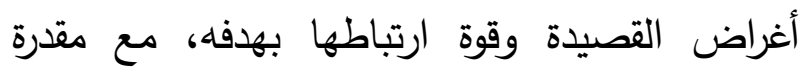
عالية على التلاعب بأقسام القصيدة للاستفادة منها للدلالة على المعاني التي يقصد إليها. بدأ حافظ داليته بغرض الغزل وقسمه إلى قسمين، وجعل القسم الأول منه (الغزل العذري) -الذي بدأ فيه بتأكيد صفة الفضيلة الخلقية لممدوحه- مقدمةً للقسم الثاني (الغزل الصريح). ومن ثم أتى حافظ بالقسم الثاني من غرض الغزل (الغزل الصريح)؛

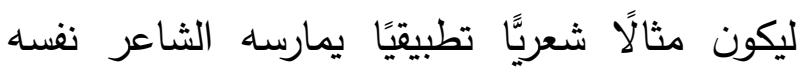

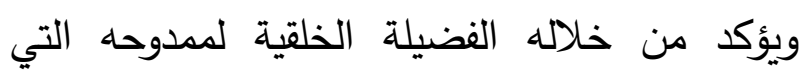
أثبتها له في القسم الأول من غرض الغزل، وذلك عن طريق تأكيده اتباع قدوته البارودي في الاتصاف غرض التهن

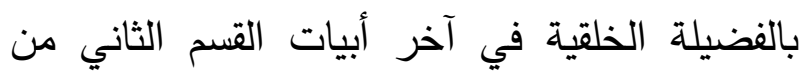
غرض الغزل. وبناء على ذلك، فإن حافظ إبراهيم لم يجعل القسم الأول من القصيدة (غرض الغ الغزل)

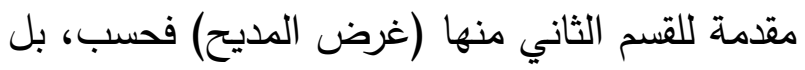
جعله مديحًا ضمنيًّا يمهّدّا من خلاله للقسم الثاني

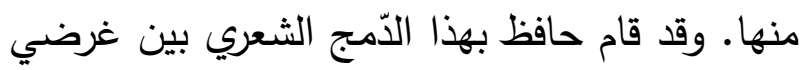
القصيدة بطريقة انسيابية سلسة لا يشعر فيها القارئ

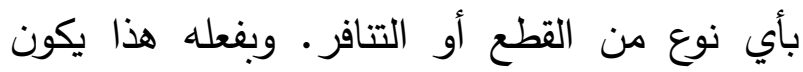
طبيعة الصوت الثعري في القصيدتين مناسبة لغرض كلا الثاعرين، كما أنها تظهر وعيهما بكيفية استخدام بنية القصيدة بأغراضها وأقسامها وعلاقة الصوت الثعري بغرض الثاعر. أشرنا أعلاه إلى أن حافظ إبراهيم قد قسم قصيدته إلى لى

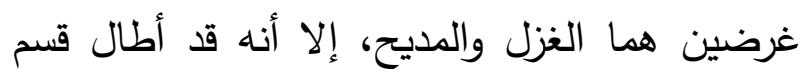
الغزل إطالة واضحة في مقابل قسم المديح، كما أنه دمج نوعين من الغزل -العذري والصريح- تحت لهت

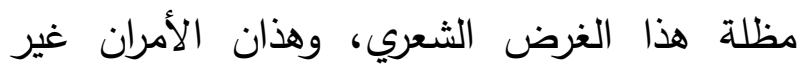
مألوفين في التقليد الشعري العربي المتعارف عليه. هذا الفعل الشعري يجعل القارئ يتساءل عن السبب

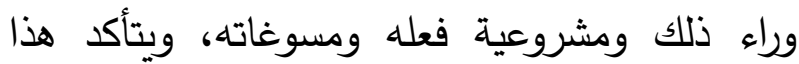

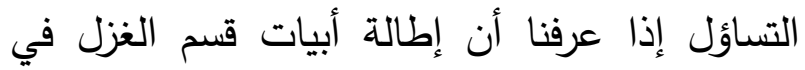
مقابل أبيات قسم المديح يعدّ -كما ذكرنا أعلاهعيبًا في التراث الشعري العربي؛ لما فيه من تجاهل غير مباشر للمدوح يفضي إلى الانتقاص من شأنه.

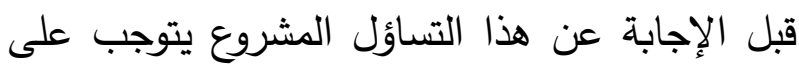
الدراسة أن تشير إلى نقطة مهمة تتعلق بقضية

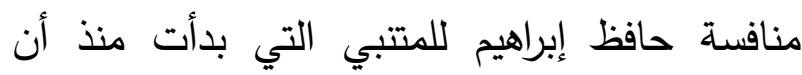
أدخل حافظ نفسه في مفهوم المعارضة الشعرية، وصرّح بها في البيت (آM) من قصيدته. هذه المنافسة تتخلل القصيدة بأكملها، ومن ذلك التلاعب بشكل القصيدة وتسخيره لخدمة الغرض العام منها؛ وهو -بالنسبة لحافظ- إثبات المقدرة الشعرية لتأكيد الأحقية بمكانة الخلافة الشعرية كما أشارت الدراسة 
يحتجْ إلى تطويله وتكريره" (ابن طباطبا، 910 ()). ومما سبق نجد أن حافظ إبراهيم يؤكد في قصيدته أمرين أساسين جعلا ممدوحه يستحق منزلة الخلافة الثعرية في عصره، وهما الفضيلة الخُلقية كما اتضح هنح من قسم الغزل، والمكانة الشعرية العليا كما اتضح من قسم المديح. ومما لا شك فيه أن المهارة الشعرية لهية

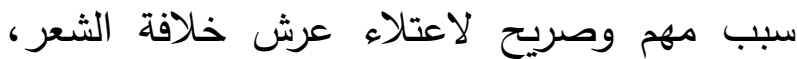

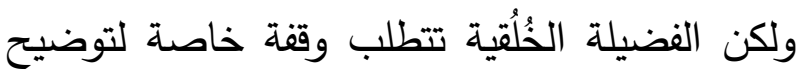
أهميتها في تحديد منزلة الثاعر في العصر الحديث.

معيار الفضيلة وإعادة ترتيب التسلسل الهرمي داخل

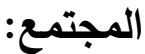
لكي يتضح السبب الذي جعل حافظ إبراهيم يؤكد ميزة الفضيلة الخُلقية ويعدّها إحدى الخاصيتين الأساسيتين اللتين أهلتا البارودي لمنصب الخلافة Yaseen الشعرية على الدراسة أن تستعرض نظرية Noorani المختلفة في العصرين القديم والحديث من حيث أهمية توفرها لدى الفرد/الممدوح لاعتلاء هرم

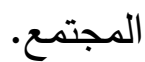

Culture and ) في كتابه Noorani أشع: Hegemony in the Colonial Middle إلى (المعنى الجديد لفضيلة وعلاقتها (East) بظهور القومية العربية)، ووفقًا لمناقشته فإن " ظهور القومية في الثرق الأوسط في أواخر القرن التاسع عر يتطلب طريقة جديدة لتصور العلاقة بين الذات
حافظ قد تجاوز فكرة التخلُص التقليدية ليتابع ما طالب به أئعة النقد القديم من ضرورة اتصال النسيب بما بعده من غرض شعري، فقد نقل ابن رشيق في كتابه العمدة رأي الحاتمي في ذلك حين قال: "من حكم النسيب الذي يفتتح به الثاعر كلامه أن يكون

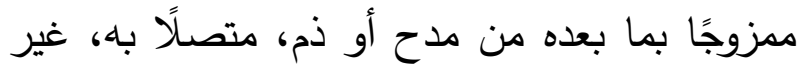
منفصل منه، فإن القصيدة مثلها مثل خلق الإنسان في اتصال بعض أعضائه ببعض، فمتى انفصل واحد عن الآخر وباينه في صحة التركيب غادر بالجسم عاهة تتخوّن محاسنه، وتعفّي معالم جماله،

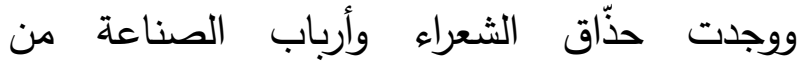
المحثثين يحترسون من مثل هذه الحال احتراسًا يحميهم من شوائب النقصان، ويقف بهم على محجّة الإحسان" (ابن رشيق، 1911 (1). وقد أشار ابن لغوان طباطبا في كتابه (عيار الشعر) إلى قواعد مهمة لبناء القصيدة، وذكر منها ما يتعلق بضرورة

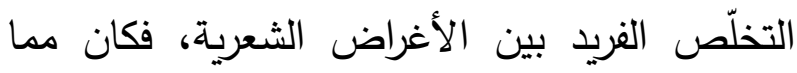
أورده في ذلك وصفه للشاعر الجيّّ بأنه: "يسلك منهاج أصحاب الرسائل في بلاغاتهم وتصرفهم في

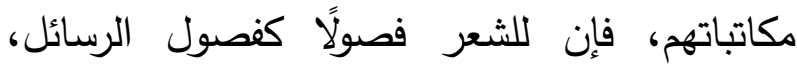
فيحتاج الثاعر إلى أن يصل كلامه -على تصرفه في فنونه- صلة لطيفة فيتخلص من الغزل إلى لى لئل المديح .... بألطف تخلّص وأحسن حكاية بلا

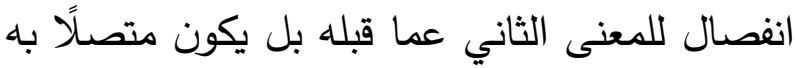
ممتزجًا مععه، فإذا استقصى المعنى وأحاط بالمراد الذي إليه يسوق القول بأيسر وصف وأخف لفظ لم 
يغيّر مفهوم الفضيلة التقليدي السائد في التاريخ العربي الإسلامي وذلك عن طريق تتاول هذا المفهوم بشكل جديد يؤكد من خلاله أن الفضيلة تتحقق في أفراد المجتمع كما تتحقق في الحاكم، بل يمكن أن يتجاوزوه فيها؛ لذا نجده يؤكد إمكانية تحقق الفضيلة وقابليتها للتطبيق من قبل أعضاء المجتمع كافة. ويهدف البارودي عن طريق ترويجه لمفهوم الفضيلة

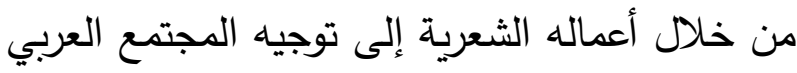
ليتمكنوا من تطبيق الفضيلة في جميع مجالات حياتهم الحديثة، ومن ثم تجاوز المشاركة التقليدية في السلطة السياسية الجديدة إلى أخذ الأدوار القيادية

وبناء على صياغة نظرية Noorani التي

تُعَبِّر اهتمام البارودي بمكمن الفضيلة، فإن الدراسة

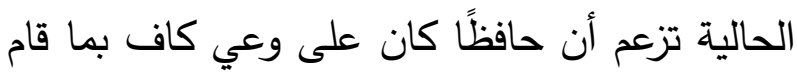

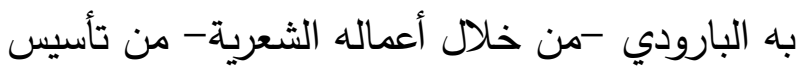
لدور الفضيلة في عملية تغيير الترتيب داخل التسلسل الهرمي الاجتماعي في العالم العربي الإسلامي. بالإضافة إلى معرفته بإصرار البارودي على ضرورة تفعيل دور الفرد الفاضل في تشكيل العلاقة المتبادلة مع مجتمعه؛ ليجعله مجتمعًا فاضلاً أيضًا، وذلك عن طريق تغيير فلسفة أفراده تجاه الحياة وتشجيعهم للتوحد والمقاومة والثورة على الظلم. وبناء على ذلك، فقد كان حافظ إبراهيم يعلم أن البارودي قد أكّد الدور المهم للشاعر في المجتمع، وأن شعره هو وسيلة مهمة لترويج الفضيلة وبناء قوة
الفردية والنظام الاجتماعي، وهي طريقة جديدة لفهم اندماج الأفراد في المجتمع الذي يعد بنية أخلاقية

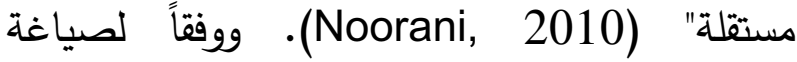
النظرية عند Noorani، فإن الفضيلة -كمعيار

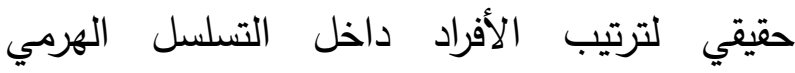
الاجتماعي- في نظام الدولة الحديثة تكمن في

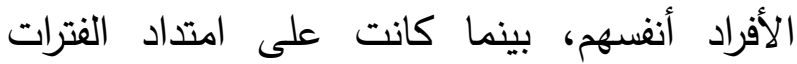
التاريخية في الثقافة العربية الإسلامية التقليدية الكلاسيكية تكمن بشكل رئيس في الحاكم الذي يعد

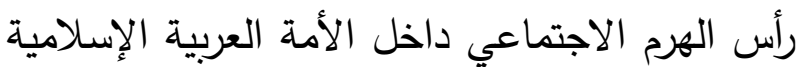

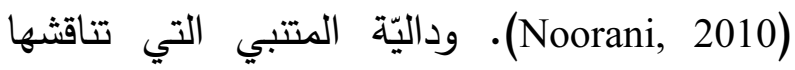
الدراسة هنا -كقصيدة تنتمي إلى إحدى هذه الفترات

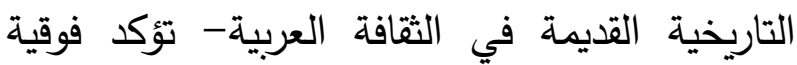
الحاكم/الأمير سيف الدولة الحمداني الاجتماعية باعتباره الأنموذج الأعلى للفضيلة بما فيه من النيك صفات استثنائية جعلته يتربع على قمة الهرم الاجتماعي(10). وفي الجانب المقابل -وبناء على هلى بتربع مقاربة Noorani لهذا المفهوم- فإن الفرد الفاضل في العصر الحديث لا يشارك في السلطة الحديثة

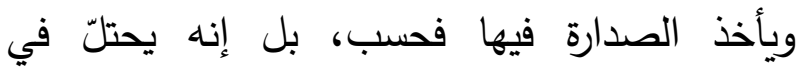
المجتمع الحديث -وبشكل أكثر أهمية- مكانة الحاكم الفاضل في العصور التقليدية القديمة. يتضح في ديوان البارودي أنه كان يحاول أن

(") يستطيع القارئ أن يتبين هذا الأمر بشكل أعمق عند قراءة قصائد

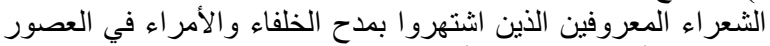

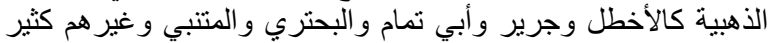

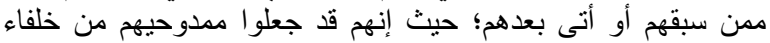
وأمر اء على قمة الهرم الاجتماعي من حيث الفضيلة. 
والشجاعة-(v') بقوله: "وجميع تلك الأفعال ونقائضها إنما تعد فضائل أو رذائل فيستوجب عليها الثناء المطلق أو الذم المطلق، ويُعتقد في صاحبها أنه خير أو شرير ، إذا حصلتُ له فيها ملكة وصارتُ له عادة لا يفارقها إلى ما ناقضها. فأن وقع المسمّى فضيلة منه ولم يتبعه بمثله ولا تمادى عليه لم أم أم يستحق أن يسمى فاضلًا ولا أن يُثنى عليه الثناء المطلق. وعلى هذا يجب أيضًا أن يكون الاعتبار في وقوع الفعل المسمى رذيلة، فاعلم ذلك" (القرطاجني، 919 1 ). وإثبات حافظ إبراهيم صفة الفضيلة للبارودي مقصود؛ ليؤكد من خلالها ضرورة اندماج الشاعر في مجتمعه بشكل كامل، ودوره كقدوة قيادية فيه، وهو العامل الذي يعد الأهم في تشكيل الأمة القوية. وبناء على المناقشة السابقة، يظهر ما للبارودي من أثر واضح في تغيير هوية الشعر عن طريق تسخيره لإنتاجه الشعري لترويج دفهوم الفضيلة الأخلاقية التي هي من أهم رسائل الشاعر الإحيائي ووسائله لتحقيق نهضة الشعر العربي الحديث. وعليه، فتؤكد الدراسة أن السبب وراء إصرار حافظ إبراهيم على ذكر صفة الفضيلة الخلقية في مدحه للبارودي، ومن ثم إثباتها لنفسه هو بيان أهميتها في تحديد منزلة الثاعر داخل الهرم الاجتماعي في العصر الحديث.

(") لمزيد من الإيضاح حول رأي أبي الفرج قدامة بن جعفر في الفضائل التي يكون بها المدح الحقيقي، انظر : (ابن جعفر ، د.ت التر).
مجتمعية فاضلة(1) - (1).

وعامل الفضيلة الذي أشار حافظ إبراهيم إلى تحققه في شخصية البارودي يؤكد "أن قدرة الأفراد لتحقيق الفضيلة، أو بمعنى آخر التحكم في الذات، وبالتالي القيام بدور مهم في خلق نظام اجتماعي، ليس أمرًا عشوائيًا، بل يتطلب تقدمًا عظيمًا في المعرفة وممارسة شاقة لضبط النفس. وعليه، فإن درجة الفضيلة التي يبلغها الفرد تتناسب مع درجة (Noorani, "السلطة الاجتماعية الجدير بها (2010. ولقد أثبت حافظ ذلك في غرضَيْ القصيدة حين مدح الباروديَّ ضمنيًا في غرض الغزل مؤكدًا قدرته العالية على ضبط النفس، ومدحه صراحة في غرض المديح مؤكدًا تقدُّمه معرفيَّا وما يتمتع به من ثقافة شعرية واسعة. ولم يشاًْ حافظ إبراهيم تأكيد -من خلاهل قسم الغزل- الفضيلة الخلقية التي يتحلى بها البارودي فحسب، بل أراد أن يجعلها تبدو كعادة متمثلة فيه ومَلكَة تهبه الأحقية بأن يكون شاعرًا فاضلًا قدوة مؤثرًا في غيره من مجايليه ومتّبعي خطاه من الشعراء. وبهذا الفعل الشعري يوافق حافظ إبراهيم قول القرطاجني حين علّق على تقسيم أبي الفرج قدامة بن جعفر الرباعي للفضائل التي يكون بها المدح الحقيقي وهي العقل والعفة والعدل

(77 (") ناقش الباحث بشكل مفصّل مفهوم الفضيلة (virute) ودور البارودي

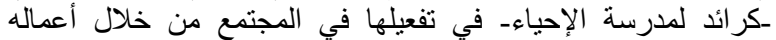

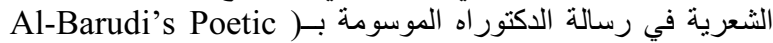
(Revival Project

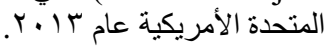


الصفتين الرئيستين لاستحقاق البارودي موقع الريادة الشعرية في العصر الحديث. وليجعل نفسه مؤهلً للخلافة الشعرية كان على حافظ إبراهيم أن يجاري البارودي في الصفتين السابقتين ويشبت تأثره به فيهما؛ لذا نجده يحرص في ختام قصيدته -تمامًا كما حرص على ذلك في بدايتها- على ربْط صوته الثعري بصوت البارودي حين أثبت له ولممدوحه صفة الفضيلة في قسم الغزل وصفة المقدرة الشعرية المتميزة في قسم المديح. فكأن حافظ وهو يمدح خُلقق البارودي وشعره يمدح خُلُقه وشعره هو، محاولًا بذلك تأكيد الاندماج بين الشخصيتين على مستويي الخُلق الإنساني والفكر الشعري؛ ليبرر استحقاقه للخلافة الشعرية من بعده. وبناء على ذلك فقد اتضح في نهاية الدراسة تحقُّقُ هدف حافظ إبراهيم من قصيدة المديح إذ تمكّنَ من الاحتفاء بمكانة الشاعر محمود سامي البارودي الشعرية، ومبايعته بأمارة الشعر وطلب الخلافة الشعرية منه. وقد أثبتتُ الدراسة أن المشروع الإحيائي الذي أراد حافظ إبراهيم أن يكون جزعًا رئيسًا منه من خلال إنتاجه الشعري -ممثنَّلَ في قصيدة مديحه الداليّةيعدّ رسالة رفيعة ومقامًا شريفًا لشعراء مدرسة الإحياء في الأدب العربي الحديث. وبناء على ذلك، فمن أراد أن يبحث في درر الإنتاج الشعري لشعراء هذه المدرسة الإحيائية التي شرُفت بتحمل مسؤولية نهضة الثعر العربي سيجد أمثلة شعرية كثيرة تحمل عبقًا لأروقة مضيئة من البلاغة لا تقف عند شاعر
وكما قام حافظ إبراهيم بإثبات هذه الصفة للبارودي ليبين سبب أحقيته للخلافة الشعرية، فقد قام بإثباتها لنفسه ليبين أحقيته للخلافة الشعرية من بعده كذلك.

\section{خاتمة}

هدفَ البحثُ إلى دراسة قصيدة حافظ إبراهيم الداليّة التي مدح بها رائد نهضة الشعر الحديث محمود سامي البارودي لبيان دورها في عملية البيعة بالخلافة الشعرية للمددوح وطلب الخلافة للشاعر المادح. وقد وضحت الدراسة أن الشاعر الإحيائي حافظ إبراهيم كان مهتمًا بإعلان مقدرته الشعرية وإظهار أهليته للقيام بدور خلافة الشعر بعد البارودي من خلال قصيدته الداليّة التي ضمّنها أمورًا فنية متعددة ومترابطة، منها: تقديم قصيدة المديح في قالب المعارضة الثعرية للمتنبي، وتأكيد حضور صوته الشعري بدمج شخصيته بشخصية ممدوحه منذ مطلع القصيدة إلى منتهاها، واستعراض مهارته الشعرية عن طريق التلاعب بالأغراض الشعرية للقصيدة وإعادة تشكيل أقسامها بما يخدم الهدف العام من مديحه، وتأكيد عامل الفضيلة كمعيار للريادة يمكن تحققه في أفراد المجتمع الحديث، وأن الفرد الفاضل - لاسيما الشاعر - يصعد في ترتيب التسلسل الهرمي للمجتمع لتكون له السلطة الحقيقية

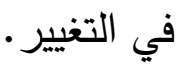
وقد بينتْ الدراسة مدى حرص حافظ إبراهيم على أن يمدح البارودي في قصيدته بالفضيلة والمقدرة الشعرية تحديدًا، وكيف أنه قد جعلهما 
وتصحيح وشرح وترتيب: أحمد أمين وأحمد الزين وإبراهيم الإبياري، طب القاهرة: الهيئة المصرية العامة

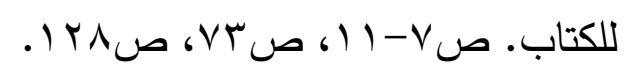
الحديدي، ع. (979) محمود سامي البارودي شاعر النهضة، طب القاهرة: مطابع سجل العرب.

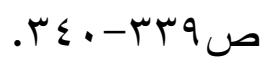
الحمداني، ح. (ع 9 ( ) ديوان أبي فراس الحمداني، جمع وتعليق: سامي الدهان، بيروت: مكتبة مروان

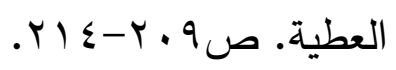

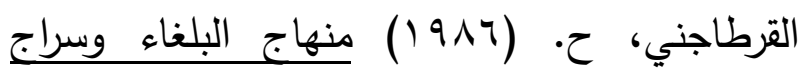
الأدباء، تحقيق: محمد الحبيب ابن الخوجة، طم

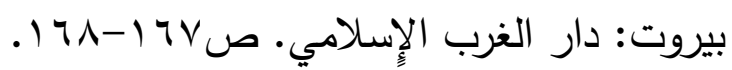

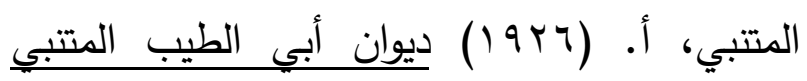
بشرح أبي البقاء العكبري (التبيان في شرح الديوان)،

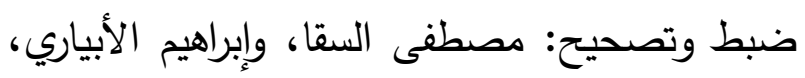
وعبد الحفيظ شلبي، مصر : مطبعة مصطفى البابي

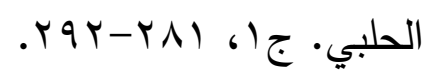

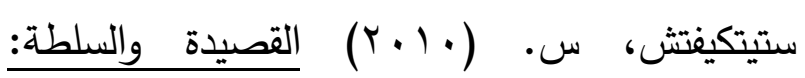
الأسطورة، الجنوسة، والمراسم في القصيدة العربية الكلاسيكية، ترجمة وتقديم: حسن البنا عز الدين،

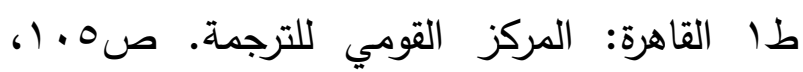

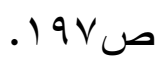

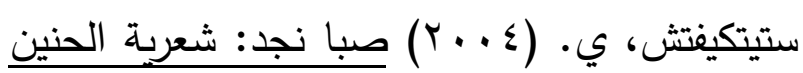
في النسيب العربي الكلاسيكي، ترجمة: حسن البنا عز الدين، الرياض: مركز الملك فيصل للبحوث والدراسات الإسلامية. صـ19 1.
إحيائي محدد. وتوصي الدراسة الباحثين بالمزاوجة بين النظريات والمفاهيم والآراء النقدية العربية والغربية لمقاربة النصوص الإحيائية لتكون زادًا للمتلقي الحديث في مسيرته الأدبية وتأكيدًا على عالمية ثقافتتا العربية.

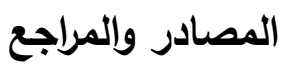

ابن جعفر، ق. (د. ت) نقد الشعر، تحقيق: محمد عبد المنعم خفاجي، بيروت: دار الكتب العلمية.

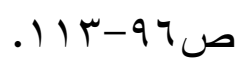
ابن رشيق، ح. (19191) العددة في محاسن الشعر وآدابه ونقده، تحقيق وتعليق: محمد محيي الدين عبد

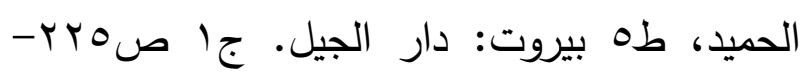
rrr ابن طباطبا، م. (9100) (1900 عيار الشعر، تحقيق: عبد العزيز ناصر المانع، الرياض: دار العلوم للطباعة

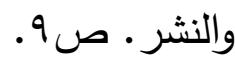
البارودي، م. (1991) ديوان البارودي، تحقيق: علي الجارم ومحمد شفيق معروف، بيروت: دار

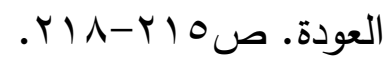

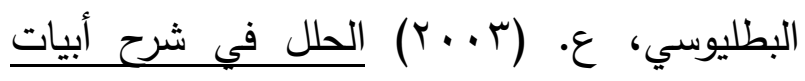
الجمل، تحقيق: يحيى مراد، طا بيروت: دار الكتب العلمية. ج ا، ص. . . 1. البغدادي، ع. (991 (19) خزانة الأدب ولب لباب لسان العرب، تحقيق: محمد نبيل طريفي وأميل بديع اليعقوب، طا بيروت: دار الكتب العالمية. جء،

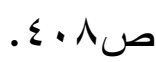
حافظ، إ. ( 9 ( ) ديوان حافظ إبراهيم، ضبط 
Mauss, M. (1967) The Gift: Forms and Functions of Exchange in Archaic Societies. Trans. Ian Cunnison. Norton and Co, New York. p9-75.

Noorani, Y. (2010) Culture and Hegemony in the Colonial Middle East, Palgrave Macmillan, N.Y. p.23-48.

Stetkevych, S. (2010) The Mantle Odes: Arabic Praise Poems to the Prophet Muhammad, Indiana University Press,
Bloomington and Indianapolis. p156. (1993) The Mute Immortals Speak: PreIslamic Poetry and the Poetics of Ritual, Cornell University Press, Ithaca, N. Y. p87157.

- (2002) The Poetics of Islamic Legitimacy: Myth, Gender, and Ceremony in the Classical Arabic Ode, Indiana University Press, Bloomington and Indianapolis. pix, p2, p34, p144-179, p245-269. 


\title{
The Iḥyā'/Revival Panegyric poem: Allegiance and Succession
}

\author{
Abdulmueen Hassan Balfas \\ Faculty of Arts and Humanities / King Abdulaziz University
}

\begin{abstract}
The study examines Hāfidh Ibrāhīm's panegyric madīh poem to the Neo-Classical pioneer poet, Maḥmūd Sāmī al-Bārūdī, whose poetry is the cornerstone of the Neo-Classical School in the Modern Arabic literature. The main objective of this study is to understand the status of al-Bārūdī as the precursor of the Arab poetic revival of the modern age and of Hăfidh as his successor. The poem acts as a poetic allegiance to alBārūdī on one hand, and a supplication for succession on the other. To support the descriptive approach which employs the critical analysis of the poetic texts, the study focuses on significant concepts such as Hāfidh Ibrāhīm's panegyric madīh poem as a poetic contrafaction (Mu'āradha) of al-Mutanabbi's dāliyyah, Hāfidh's poetic voice (lyric I), the reconstruction of the traditional qasīdah with its themes and sections, and virtue as an essential factor for leadership in modern Arab community.
\end{abstract}

Keywords: Hafidh Ibrahim, al-Barudi, al-Mutanabbi, Poetic Succession, Poetic allegiance. 